\title{
Homotopy Method for Solving Finite Level Fuzzy Nonlinear Integral Equation
}

\author{
Alan Jalal Abdulqader \\ University Gadjah mada, Department of Mathematics and atural Science, Faculty MIPA, Yogyakarta, Indonesia \\ Email address: \\ alanjala1515@yahoo.com \\ To cite this article: \\ Alan Jalal Abdulqader. Homotopy Method for Solvind Finite Level Fuzzy Nonlinear Integral Equation. Applied and Computational \\ Mathematics. Vol. 4, No. 4, 2015, pp. 245-257. doi: 10.11648/j.acm.20150404.13
}

\begin{abstract}
In this paper, non - linear finite fuzzy Volterra integral equation of the second kind (NFVIEK2) is considered. The Homotopy analysis method will be used to solve it, and comparing with the exact solution and calculate the absolute error between them. Some numerical examples are prepared to show the efficiency and simplicity of the method.
\end{abstract}

Keywords: Fuzzy Number, Finite Level, Volterra Integral Equation of Second Kind, Homotopy Analysis Method, Fuzzy Integral

\section{Introduction}

In this chapter, we construct a new method to find a solution of the nonlinear fuzzy integral equation.

$$
\left.\widetilde{\mathrm{u}}(\mathrm{x})=\tilde{\mathrm{f}}(\mathrm{x})+\lambda \int_{\mathrm{a}}^{\mathrm{b}} \tilde{\mathrm{k}}(\mathrm{x}, \mathrm{t}) \tilde{\mathrm{u}}(\mathrm{t})\right) \mathrm{dt}
$$

where $\widetilde{\mathrm{u}}, \tilde{\mathrm{f}}$ and $\tilde{\mathrm{k}}$ are fuzzy functions. Park et al., consider the existence of solution of fuzzy integral equations in Banach spaces. But unfortunately, we could not see the proof of the existence theorem, For this reason, we prove the existence theorem for the solution of fuzzy integral equations by extending the existence theorems for ordinary integral equations, and we think that our approach different from the approach of those authors. So we need some background material about fuzzy metric space, fuzzy contraction mapping and related mathematical notions. These notions are fundamental, and absolutely essential in proving the existence and uniqueness of (1) .We will discuss some method in order to find the solutions of nonlinear fuzzy integral equation of second kind.

\section{Basic Concepts}

Let $X$ be a space of object, let $\widetilde{A}$ be a fuzzy set in $X$ then one can define the following concepts related to fuzzy subset $\widetilde{A}$ of $X[1,6]$ : by :

1- The support of $\widetilde{A}$ in the universal $X$ is crisp set, denoted

$$
\mathrm{S}(\widetilde{\mathrm{A}})=\left\{\mathrm{x} \in \mathrm{X} \mid \mu_{\widetilde{\mathrm{A}}}(\mathrm{x})>0\right\} .
$$

2- The core of a fuzzy set $\widetilde{A}$ is the set of all point $x \in X$, such that $\mu_{\widetilde{A}}(\mathrm{x})=1$

3- The height of a fuzzy set $\widetilde{A}$ is the largest membership grade over $X$, i.e $\operatorname{hgt}(\widetilde{\mathrm{A}})=\sup _{\mathrm{x} \in \mathrm{X}} \mu_{\widetilde{\mathrm{A}}}(\mathrm{x})$

4- Crossover point of a fuzzy set $\widetilde{A}$ is the point in $X$ whose grade of membership in $\widetilde{\mathrm{A}}$ is 0.5

5- Fuzzy singleton is a fuzzy set whose support is single point in $\mathrm{X}$ with $\mu_{\widetilde{\mathrm{A}}}(\mathrm{x})=1$

6- A fuzzy set $\widetilde{A}$ is called normalized if it's height is 1 ; otherwise it is subnormal

Note:

A non-empty fuzzy set $\widetilde{A}$ can always be normalized by dividing

$$
\mu_{\widetilde{\mathrm{A}}}(\mathrm{x}) \text { by } \sup _{\mathrm{x} \in \mathrm{X}} \mu_{\widetilde{\mathrm{A}}}(\mathrm{x})
$$

7-The empty set $\phi$ and $X$ are fuzzy set, then: for all $x \in$ $\mathrm{X}, \mu_{\phi}(\mathrm{x})=0, \mu_{\mathrm{x}}(\mathrm{x})=1$ respectively

8- $A=B$ if and only if $\mu_{A}(x)=\mu_{B}(x)$ for all $x \in X$

9- $\mathrm{A} \subseteq \mathrm{B}$ if and only if $\mu_{\mathrm{A}}(\mathrm{x}) \leq \mu_{\mathrm{B}}(\mathrm{x})$ for all $\mathrm{x} \in \mathrm{X}$

$10-\widetilde{A}^{c}$ is a fuzzy set whose membership function is defined by $\mu_{\widetilde{\mathrm{A}}^{c}}(\mathrm{x})=1-\mu_{\widetilde{\mathrm{A}}}(\mathrm{x})$ for all $\mathrm{x} \in \mathrm{X}$

11-Given two fuzzy sets, $\widetilde{A}$ and $\widetilde{B}$, their standard intersection, $\widetilde{\mathrm{A}} \sqcap \widetilde{\mathrm{B}}$, and the standard union $\widetilde{\mathrm{A}} \sqcup \widetilde{\mathrm{B}}$, are fuzzy sets and their membership function are defined for all $\mathrm{x} \in \mathrm{X}$, by the equations:

$$
\forall \mathrm{x} \in \mathrm{X}, \mu_{\mathrm{A} \cup \mathrm{B}}(\mathrm{x})=\operatorname{Max}\left[\mu_{\mathrm{A}}(\mathrm{x}), \mu_{\mathrm{B}}(\mathrm{x})\right]
$$




$$
\forall \mathrm{x} \in \mathrm{X}, \mu_{\mathrm{A} \cap \mathrm{B}}(\mathrm{x})=\operatorname{Min}\left[\mu_{\mathrm{A}}(\mathrm{x}), \mu_{\mathrm{B}}(\mathrm{x})\right]
$$

\section{3. $\alpha$ - Cut Sets}

Definition 1: ( $\alpha$ - cut set) The $\alpha$-cut set $\mathrm{A}_{\alpha}$ of a fuzzy set $A$ is made up of membership whose membership is not less than $\alpha,[3,5,9]$

$$
\mathrm{A}_{\alpha}=\left\{\mathrm{x} \in \mathrm{X}: \mu_{\mathrm{A}}(\mathrm{x}) \geq \alpha\right\}, \forall \mathrm{x} \in \mathrm{X}
$$

The following properties are satisfied for all $\alpha \in[0,1]$

i- $\quad(A \cup B)_{\alpha}=A_{\alpha} \cup B_{\alpha}$

ii- $\quad(A \cap B)_{\alpha}=A_{\alpha} \cap B_{\alpha}$

iii- $\mathrm{A} \subseteq$ B gives $\mathrm{A}_{\alpha} \subseteq \mathrm{B}_{\alpha}$

iv- $A=B$ iff $A_{\alpha}=B_{\alpha}, \forall \alpha \in[0,1]$

v- $\quad \alpha \leq \alpha^{\prime}$ then $\mathrm{A}_{\alpha} \supseteq \mathrm{A}_{\alpha^{\prime}}$

Remarks 3:

1 - The set of all level $\alpha \in[0,1]$, that represent distinct $\alpha-$ cuts of a given fuzzy set [17]

$\widetilde{\mathrm{A}}$ is called a level set of $\widetilde{\mathrm{A}}$

$$
\Lambda(\widetilde{\mathrm{A}})=\left\{\alpha \mid \mu_{\widetilde{\mathrm{A}}}(\mathrm{x})=\alpha, \text { for some } \mathrm{x} \in \mathrm{X}\right\}
$$

2- The support of $\widetilde{A}$ is exactly the same as the strong $\alpha-$ cut of $\widetilde{A}$ for $\alpha=0, \mathrm{~A}_{0+}=\mathrm{S}(\widetilde{\mathrm{A}})$.

3 - The core of $\widetilde{\mathrm{A}}$ is exactly the same as the $\alpha$ - cut of $\widetilde{\mathrm{A}}$ for $\alpha=1$, (i. e $A_{1}=\operatorname{core}(\widetilde{A})$ ).

4- The height of $\widetilde{A}$ may also be viewed as the supremum of $\alpha-$ cut for which $\mathrm{A}_{\alpha} \neq \phi$

5- The membership function of a fuzzy set $\widetilde{A}$ can be expressed in terms of the characteristic function of it is $\alpha$ - cuts according to the formula:

$$
\mu_{\widetilde{A}}(\mathrm{x})=\sup _{\alpha \in] 0,1]} \operatorname{Min}\left\{\alpha, \mu_{\mathrm{A}^{\alpha}}(\mathrm{x})\right\}
$$

Where

$$
\mu_{A^{\alpha}}(x)=\left\{\begin{array}{c}
1 \text { if } x \in A_{\alpha} \\
0, \text { otherwise }
\end{array}\right.
$$

\section{Convex Fuzzy Sets}

We can generalize the definition of convexity to fuzzy sets. Assuming universal set $\mathrm{X}$ is defined in the set of real numbers $\mathrm{R}$. If all $\alpha$-cut sets are convex, then the fuzzy set with these $\alpha-$ cut sets is convex $[12,20]$

Definition 2:

$$
\mu_{\mathrm{B}}(\mathrm{y})=\left\{\begin{array}{c}
\operatorname{Sup}\left\{\operatorname{Min}\left(\mu_{\mathrm{A}_{1}}\left(\mathrm{X}_{1}\right), \ldots \ldots \ldots, \mu_{\mathrm{A}_{\mathrm{r}}}\left(\mathrm{X}_{\mathrm{r}}\right) \mid \mathrm{x}_{\mathrm{i}} \in \mathrm{X}_{\mathrm{i}}, \mathrm{i}=1,2,3 \ldots \ldots, \mathrm{n}, \mathrm{y}=\mathrm{f}\left(\mathrm{x}_{1} \times \ldots . . \times \mathrm{x}_{\mathrm{r}}\right)\right\}\right. \\
0, \text { if }^{-1}(\mathrm{y})=\phi
\end{array}\right.
$$

Here, $f^{-1}(y)$ is the inverse image of $y, \mu_{B}(y)$ is the membership of $=f\left(x_{1} \times \ldots . . \times x_{r}\right)$

In following example, we will show that fuzzy distance between fuzzy sets can be defined by extension principle.

\section{Intervals}

"real number" implies a set containing whole real numbers and "positive numbers" implies a set holding numbers excluding negative numbers. "positive number less than
A fuzzy set $\widetilde{A}$ on $R$ is convex if and only if [13] :

$$
\mu_{\widetilde{\mathrm{A}}}\left(\lambda \mathrm{x}_{1}+(1-\lambda) \mathrm{x}_{2}\right) \geq \operatorname{Min}\left\{\mu_{\widetilde{\mathrm{A}}}\left(\mathrm{x}_{1}\right), \mu_{\widetilde{\mathrm{A}}}\left(\mathrm{x}_{2}\right)\right\}
$$

for all $\mathrm{x}_{1}, \mathrm{x}_{2} \in \mathrm{R}$, and all $\lambda \in[0,1]$

Remarks 4:

Assume that $\widetilde{A}$ is convex for all $\alpha$ and let $\alpha=$ $\mu_{\widetilde{\mathrm{A}}}\left(\mathrm{x}_{1}\right), \mu_{\widetilde{\mathrm{A}}}\left(\mathrm{x}_{2}\right)$ then if $\mathrm{x}_{1}, \mathrm{x}_{2} \in \mathrm{A}_{\alpha}$ and moreover $\lambda \mathrm{x}_{1}+$ $(1-\lambda) x_{2} \in A_{\alpha}$ for any $\lambda \in[0,1]$ by the convexity of $\widetilde{A}$. Consequently

$$
\begin{gathered}
\mu_{\widetilde{\mathrm{A}}}\left(\lambda \mathrm{x}_{1}+(1-\lambda) \mathrm{x}_{2}\right) \geq \alpha=\mu_{\widetilde{\mathrm{A}}}\left(\mathrm{x}_{1}\right)= \\
\operatorname{Min}\left\{\mu_{\widetilde{\mathrm{A}}}\left(\mathrm{x}_{1}\right), \mu_{\widetilde{\mathrm{A}}}\left(\mathrm{x}_{2}\right)\right\} .
\end{gathered}
$$

Assume that $\widetilde{A}$ satisfies equation (1), we need to prove that For any $\alpha \in[0,1], A_{\alpha}$ is convex. Now for any $x_{1}, x_{2} \in A_{\alpha}$ and for any $\lambda \in[0,1]$ by equation (1)

$$
\mu_{\widetilde{\mathrm{A}}}\left(\lambda \mathrm{x}_{1}+(1-\lambda) \mathrm{x}_{2}\right) \geq \operatorname{Min}\left\{\mu_{\widetilde{\mathrm{A}}}\left(\mathrm{x}_{1}\right), \mu_{\widetilde{\mathrm{A}}}\left(\mathrm{x}_{2}\right)\right\} \geq \operatorname{Min}\{\alpha, \alpha\}=\alpha
$$

i.e

$\lambda \mathrm{x}_{1}+(1-\lambda) \mathrm{x}_{2} \in \mathrm{A}_{\alpha}$, therefore $\mathrm{A}_{\alpha}$ is convex for any $\alpha \in$ $[0,1], \widetilde{A}$ is convex.

Definition 3. (Extension of fuzzy set ) Let $f: X \rightarrow Y$, and $A$ be a fuzzy set defined on $X$, then we can obtain a fuzzy set $\mathrm{f}(\mathrm{A})$ in $\mathrm{Y}$ by $\mathrm{f}$ and $\mathrm{A}[14,23]$

$$
\begin{gathered}
\forall y \in Y, \mu_{\mathrm{f}(\mathrm{A})}(\mathrm{y})= \\
\left\{\begin{array}{c}
\sup \left\{\mu_{\mathrm{A}}(\mathrm{x}) \text { if }^{-1}(\mathrm{y}) \neq \phi, \forall \mathrm{x} \in \mathrm{X}, \mathrm{y}=\mathrm{f}(\mathrm{x})\right\} \\
0 \text { if }^{-1}(\mathrm{y})=\phi
\end{array}\right.
\end{gathered}
$$

Definition 4: (Extension Principle) We can generalize the per-explained extension of fuzzy set. Let $\mathrm{X}$ be Cartesian product of universal set $\mathrm{X}=\mathrm{X}_{1} \times \mathrm{X}_{2} \times \ldots \ldots \ldots$ $X_{r}$ and $A_{1}, A_{2}, \ldots \ldots \ldots, A_{r}$ be $r$ - fuzzy sets in the universal set. Cartesian product of fuzzy sets $A_{1}, A_{2}, \ldots \ldots, A_{r}$ yields a fuzzy set $[14,24,19]$

$\mathrm{A}_{1}, \mathrm{~A}_{2}, \ldots \ldots . \mathrm{A}_{\mathrm{r}}$ define as

$$
\begin{gathered}
\mu_{\mathrm{A}_{1}, \mathrm{~A}_{2}, \ldots \ldots, \mathrm{A}_{\mathrm{r}}}\left(\mathrm{X}_{1} \times \mathrm{X}_{2} \times \ldots \ldots \ldots \times \mathrm{X}_{\mathrm{r}}\right)= \\
\operatorname{Min}\left(\mu_{\mathrm{A}_{1}}\left(\mathrm{X}_{1}\right), \ldots \ldots \ldots, \mu_{\mathrm{A}_{\mathrm{r}}}\left(\mathrm{X}_{\mathrm{r}}\right)\right)
\end{gathered}
$$

Let function $\mathrm{f}$ be from space $\mathrm{X}$ and $\mathrm{Y}$

$$
\mathrm{f}\left(\mathrm{X}_{1} \times \mathrm{X}_{2} \times \ldots \ldots \ldots \mathrm{X}_{\mathrm{r}}\right): \mathrm{X} \rightarrow \mathrm{Y}
$$

Then fuzzy set $\mathrm{B}$ in $\mathrm{Y}$ can be obtained by function $\mathrm{f}$ and fuzzy sets $A_{1}, A_{2}, \ldots \ldots, A_{r}$ as follows: equal to 10 (including 0 )" suggests us a set having numbers from 0 to 10 . That is $[1,4,11,22]$

$$
A=\{x \mid 0 \leq x \leq 10, x \in R\}
$$

Or

$$
\mu_{A}(x)=\left\{\begin{array}{c}
1, \text { if } 0 \leq x \leq 10, x \in R \\
0, \text { if } x<0 \text { or } x>10
\end{array}\right.
$$

Since the crisp boundary is involved, the outcome of 
membership function is one or zero. In general, when interval is defined on set of real number $\mathrm{R}$ this interval is said to be a subset of $R$. For instance, if interval is denoted as $A=$ $\left[a_{1}, a_{3}\right], a_{1}, a_{3} \in R, a_{1}<a_{3}$, we may regard this as one kind of sets. Expressing the interval as membership function is shown in the following .

$$
\mu_{A}(x)=\left\{\begin{array}{c}
0, \text { if } x<a_{1} \\
1, \text { if } a_{1} \leq x \leq a_{3} \\
0, \text { if } x>a_{3}
\end{array}\right.
$$

If $\mathrm{a}_{1}=\mathrm{a}_{3}$, this interval indicates a point. That is

$$
\left[\mathrm{a}_{1}, \mathrm{a}_{1}\right]=\mathrm{a}_{1}
$$

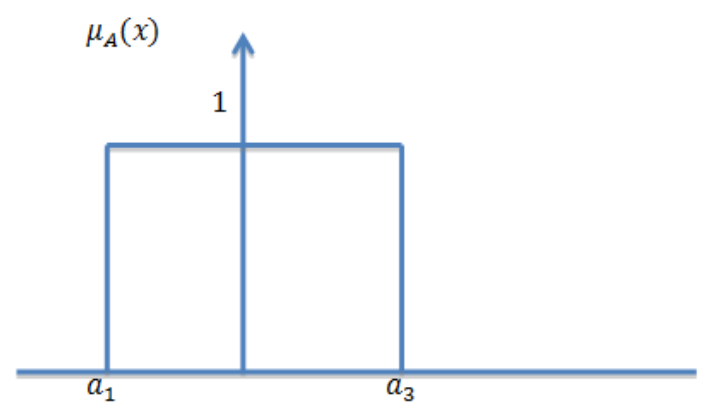

Fig. 1. Interval $A=\left[a_{1}, a_{3}\right]$.

Definition 5: (fuzzy number) If a fuzzy set is convex and normalized, and its membership function is defined in $R$ and piecewise continuous, its is called as fuzzy number so fuzzy number (fuzzy set ) represents a real number interval whose boundaries is fuzzy Fig 2, [3,26,5,6].
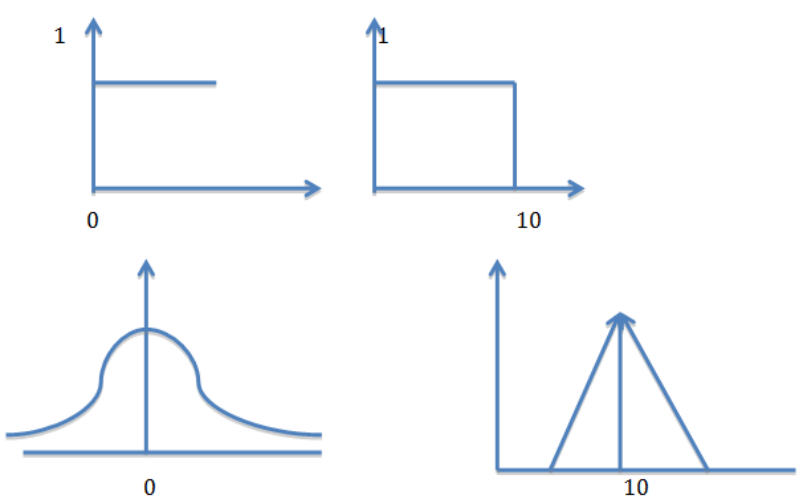

Fig. 2. Sets denoting intervals and fuzzy number.

Fuzzy number should be normalized and convex. Here the condition of normalization implies that maximum membership value is 1

$$
\exists x \in R, \mu_{A}(x)=1
$$

The convex condition is that the line by $\alpha-c u t$ is continuous and $\alpha-c u t$ interval satisfies the following relation:

$$
\begin{gathered}
A_{\alpha}=\left[a_{1}^{\alpha}, a_{3}^{\alpha}\right] \\
\left(\alpha^{\prime}<\alpha\right) \Rightarrow\left(a_{1}^{\alpha^{\prime}} \leq a_{1}^{\alpha}, a_{3}^{\alpha^{\prime}} \geq a_{3}^{\alpha}\right)
\end{gathered}
$$

This condition may also be written as,

$$
\left(\alpha^{\prime}<\alpha\right) \Rightarrow\left(A_{\alpha} \subseteq A_{\dot{\alpha}}\right)
$$

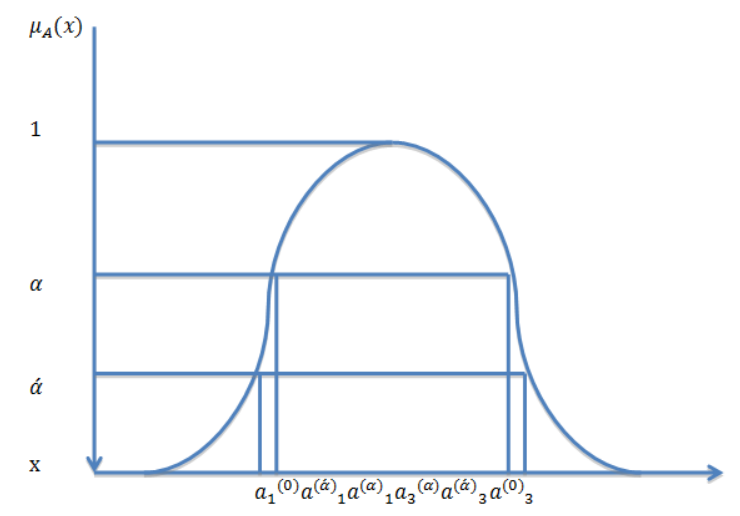

Fig. 3. $\alpha$-cut of fuzzy number.

\subsection{Operation of $\alpha-$ cut Interval}

Operation on fuzzy numbers can be generalized from that of crisp interval. First of all, we referred to $\alpha$ - cut interval of fuzzy number $A=\left[a_{1}, a_{3}\right]$ as crisp set $[8,11,10]$,

$$
\mathrm{A}_{\alpha}=\left[\mathrm{a}^{\alpha}{ }_{1}, \mathrm{a}^{\alpha}{ }_{3}\right], \forall \alpha \in[0,1], \mathrm{a}_{1}, \mathrm{a}_{3}, \mathrm{a}^{\alpha}{ }_{1}, \mathrm{a}^{\alpha}{ }_{3} \in \mathrm{R}
$$

So $A_{\alpha}$ is a crisp interval. If $\alpha-$ cut interval $B_{\alpha}$ for fuzzy number $\mathrm{B}$ is given

$$
\mathrm{B}_{\alpha}=\left[\mathrm{b}_{1}^{\alpha}, \mathrm{b}^{\alpha}{ }_{3}\right], \forall \alpha \in[0,1], \mathrm{b}_{1}, \mathrm{~b}_{3}, \mathrm{~b}^{\alpha}{ }_{1}, \mathrm{~b}^{\alpha}{ }_{3} \in \mathrm{R}
$$

operation between $A_{\alpha}$ and $B_{\alpha}$ can be described as follows $[6,15]$ :

1- Addition

$\mathrm{A}_{\alpha} \oplus \mathrm{B}_{\alpha}=\left[\mathrm{a}^{\alpha}{ }_{1}, \mathrm{a}^{\alpha}{ }_{3}\right] \oplus\left[\mathrm{b}^{\alpha}{ }_{1}, \mathrm{~b}^{\alpha}{ }_{3}\right]=\left[\mathrm{a}^{\alpha}{ }_{1}+\mathrm{b}^{\alpha}{ }_{1}, \mathrm{a}^{\alpha}{ }_{3}+\mathrm{b}^{\alpha}{ }_{3}\right]$

2- Subtraction

$A_{\alpha} \ominus B_{\alpha}=\left[a^{\alpha}{ }_{1}, a^{\alpha}{ }_{3}\right] \ominus\left[b^{\alpha}{ }_{1}, b^{\alpha}{ }_{3}\right]=\left[a^{\alpha}{ }_{1}-b^{\alpha}{ }_{3}, a^{\alpha}{ }_{3}-b^{\alpha}{ }_{1}\right]$

3- Multiplication

$$
A_{\alpha} \odot B_{\alpha}=\left[a^{\alpha}{ }_{1} \cdot b^{\alpha}{ }_{1}, a^{\alpha}{ }_{3} \cdot b^{\alpha}{ }_{3}\right]
$$

4- Division

$$
\mathrm{A}_{\alpha} / \mathrm{B}_{\alpha}=\left[\mathrm{a}^{\alpha}{ }_{1} / \mathrm{b}^{\alpha}{ }_{1}, \mathrm{a}^{\alpha}{ }_{3} / \mathrm{b}^{\alpha}{ }_{3}\right]
$$

5- Invers

$$
\mathrm{A}^{-1}{ }_{\alpha}=\left[1 / \mathrm{a}^{\alpha}{ }_{1}, 1 / \mathrm{a}^{\alpha}{ }_{3}\right]
$$

6- Minimum

$A_{\alpha} \wedge B_{\alpha}=\left[a^{\alpha}{ }_{1}, a^{\alpha}{ }_{3}\right] \wedge\left[b^{\alpha}{ }_{1}, b^{\alpha}{ }_{3}\right]=\left[a^{\alpha}{ }_{1} \wedge b^{\alpha}{ }_{1}, a^{\alpha}{ }_{3} \wedge b^{\alpha}{ }_{3}\right]$

7- Maximum

$A_{\alpha} \vee B_{\alpha}=\left[a^{\alpha}{ }_{1}, a^{\alpha}{ }_{3}\right] \vee\left[b^{\alpha}{ }_{1}, b^{\alpha}{ }_{3}\right]=\left[a^{\alpha}{ }_{1} \vee b^{\alpha}{ }_{1}, a^{\alpha}{ }_{3} \vee b^{\alpha}{ }_{3}\right]$

\subsection{Operation on Fuzzy Numbers}

Let $F(R)$ be the set of all fuzzy numbers on real line R. Using extension principle. A binary operation * can be 
extended into $(*)$ to combine two fuzzy numbers A and $\mathrm{B}$. Moreover, if $\mu_{A}$ and $\mu_{B}$ are the membership functions of $\mathrm{A}$ and $\mathrm{B}$ assumed to be continuous functions on $\mathrm{R}[2,7,16]$

$\mu_{\mathrm{A}(*) \mathrm{B}}(\mathrm{z})=\operatorname{Sup}\left\{\operatorname{Min}\left(\mu_{\mathrm{A}}(\mathrm{x}), \mu_{\mathrm{B}}(\mathrm{y}) \mid \forall \mathrm{x}, \mathrm{y} \in \mathrm{R}, \mathrm{z}=\mathrm{x} * \mathrm{y}\right\}\right.$

Theorem 1: Let A, B and $\mathrm{C}$ be a fuzzy numbers. The following holds [9]:

$$
\begin{aligned}
& \text { 1- } A(B \oplus C)=(A \cdot B) \oplus(A . C) \\
& \text { 2- }-(-\mathrm{A})=\mathrm{A} \\
& \text { 3- } \mathrm{A} \backslash 1=\mathrm{A} \\
& \text { 4- } \mathrm{A} / \mathrm{B}=\mathrm{A} .1 / \mathrm{B} \\
& \text { 5- } r(A \oplus B)=r A \oplus r B \\
& \text { 6- }(-\mathrm{r}) \mathrm{A}=-(\mathrm{rA}) \\
& \text { 7- }(-\mathrm{A}) \mathrm{B}=-(\mathrm{A} \cdot \mathrm{B})=\mathrm{A}(-\mathrm{B}) \\
& \text { 8- } \mathrm{A} / \mathrm{r}=(1 / \mathrm{r}) \mathrm{A} \\
& \text { 9- } A \oplus(-B)=A-B
\end{aligned}
$$

\section{Other Types of Fuzzy Numbers}

Carrying out computations with fuzzy quantities and in particular with fuzzy numbers, can be complicated. There are some special classes of fuzzy numbers for which computations of their sum, for example is easy. One such class is that of triangular fuzzy number, another one is that of trapezoidal fuzzy number.

In this paper we discuss about new type for fuzzy number name finite level fuzzy number[11,17,21].

Remarks 5:

Lets talk about the operation of trapezoidal fuzzy number as in the triangular fuzzy number

1. Addition and Subtraction between trapezoidal (triangular )fuzzy numbers become trapezoidal (triangular) fuzzy number

2. Multiplication, Division and inverse need not be trapezoidal (triangular) fuzzy numbers

3. Max and Min operation of trapezoidal (triangular) fuzzy numbers is not always in the form of trapezoidal (triangular) fuzzy numbers

But in may cases, the operation results from multiplication or division are approximated trapezoidal shape. As I triangular fuzzy number, addition and subtraction are simply defined, and multiplication and division operations should be done by using membership function

i- $\quad A \oplus \mathrm{B}=\left[\mathrm{a}_{1}, \mathrm{a}_{3}\right] \oplus\left[\mathrm{b}_{1}, \mathrm{~b}_{3}\right]=\left[\mathrm{a}_{1}+\mathrm{b}_{1}, \mathrm{a}_{3}+\mathrm{b}_{3}\right]$

ii- $\quad A \ominus B=\left[a_{1}, a_{3}\right] \ominus\left[b_{1}, b_{3}\right]=\left[a_{1}-b_{3}, a_{3}-b_{1}\right]$

iii- $A \odot B=\left[a_{1}, a_{3}\right] \circledast\left[b_{1}, b_{3}\right]=\left[a_{1} \cdot b_{1}, a_{3} . b_{3}\right]$

iv- symmetric image $-(A)=\left[-a_{3},-a_{1}\right]$

The multiplication and the addition of two triangular ( trapezoidal) fuzzy numbers is not a triangular (trapezoidal) fuzzy number, so it will not form a group structure. Now, we will construct a new of fuzzy numbers ( which we shall call it finite level fuzzy numbers), such that the addition and multiplication of two finite level fuzzy numbers will be also finite level fuzzy number. The construction of this new type of fuzzy numbers will as follows $[25,14,20]$ :

Given $\mathrm{n}$, $\mathrm{N}$ be two positive integers $\mathrm{n}<\mathrm{N}$, and $\alpha_{1}, \alpha_{2}, \ldots \ldots \ldots, \alpha_{\mathrm{N}} \in[0,1]$ such that

$$
\begin{gathered}
\alpha_{1}<\alpha_{2}<\cdots . .<\alpha_{n-1}<\alpha_{n}=1 \\
\alpha_{N}<\alpha_{N-1}<\cdots . .<\alpha_{n+1}<\alpha_{n}=1
\end{gathered}
$$

Let $F\left(R_{N}\right)$ be the set of all fuzzy numbers $A=\left\{\left(x_{i}, \alpha_{i}\right)\right\}_{N}$ defined on $\mathrm{R}$, such that $\mathrm{x}_{1}<\mathrm{x}_{2}<\cdots . .<\mathrm{x}_{\mathrm{N}}$

The operations of this type of fuzzy numbers can be defined by

Let $A$ and $B \in F\left(R_{N}\right)$ such that $A=\left\{\left(x_{i}, \alpha_{i}\right)\right\}_{N}$ and $B=$ $\left\{\left(\mathrm{y}_{\mathrm{i}}, \alpha_{\mathrm{i}}\right)\right\}_{\mathrm{N}}$

According to equation (2) we have

$$
\begin{aligned}
\mu_{\mathrm{A}(*) \mathrm{B}}(\mathrm{z}) & =\operatorname{Sup}\left\{\operatorname{Min}\left(\mu_{\mathrm{A}}(\mathrm{x}), \mu_{\mathrm{B}}(\mathrm{y}) \mid \forall \mathrm{x}, \mathrm{y} \in \mathrm{R}, \mathrm{z}=\mathrm{x} * \mathrm{y}\right\}\right. \\
& =\operatorname{Max}\left\{\operatorname{Min}\left(\alpha_{\mathrm{i}}, \alpha_{\mathrm{j}}\right) \mid \mathrm{z}=\mathrm{x}_{\mathrm{i}} * \mathrm{y}_{\mathrm{i}}\right\}
\end{aligned}
$$

If we perform the * operation between $\mathrm{A}$ and $\mathrm{B}$, we will get the following table

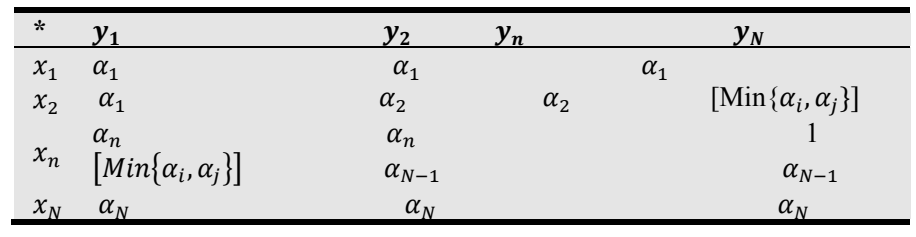

Now, from this table it is clear that the convex of $A^{*} B$ is

$$
\mu_{A(*) B}(z)=\left\{\begin{array}{c}
\alpha_{1 \text { for } x_{1} * y_{1} \leq z \leq x_{2} * y_{2}} \\
\alpha_{2} \text { for } x_{2} * y_{2} \leq z \leq x_{3} * y_{3} \\
\vdots \\
1 \text { for } z=x_{n *} y_{n} \\
\vdots \\
\alpha_{n+1} \text { for } x_{n} * y_{n} \leq z \leq x_{n+1} * y_{n+1} \\
\alpha_{N \text { for } x_{N-1} y_{N-1} \leq z \leq x_{N} * y_{N}}
\end{array}\right.
$$

According to equation ( 3 and 4 ) in this case can be written as

$$
\mu_{A(*) B}(z)=\alpha_{i}, \text { if } z=x_{i} * y_{i}
$$

where

$$
\mu_{A(*) B}(z)=1, \text { if } z=x_{n} * y_{n}
$$

and

$$
z_{1}<z_{2}<\cdots \ldots<z_{n}=x_{n} * y_{n} \text { and } x_{n} * y_{n}=z_{n}<z_{n+1}<\cdots<z_{n}
$$

So $\tilde{Z}=\left\{\left(z_{i}, \alpha_{i}\right\}_{N}\right.$ is fuzzy number and $\tilde{Z} \in F\left(R_{N}\right)$

\section{Fuzzy Equations}

A fuzzy equation is an equation whose coefficients and / or variable are fuzzy sets of $\mathrm{R}$. The concept of equation can be extended to deal with fuzzy quantities in several ways. Consider the simple equation $a x+b=x$ where $(a, b) \in$
$R, x$ is a real vareiable, and $a \neq$

1 , so that the unique solution is $x=\frac{b}{1-a}$, then the fuzzy equation

$$
\tilde{a} \tilde{x}+\tilde{b}=\tilde{x}, \tilde{a}, \tilde{b} \in \tilde{P}(R), x \in R
$$

means that the fuzzy set $\tilde{a} \tilde{x}+\tilde{b}$ is the same as $\tilde{x}$. Note that it is forbidden to shift terms from one side to another. For 
instance, the equation $\tilde{a} \tilde{x}+\tilde{b}=\tilde{x}$ is not equal to $\tilde{a} \tilde{x}+\tilde{b}-$ $\tilde{x}=0$ : the first may have solution, while the second surely dose not, since $\tilde{a} \tilde{x}+\tilde{b}-\tilde{x}$ is fuzzy and 0 is scalar.

We can solve the fuzzy equation (6) if we consider the fuzzy variables and the fuzzy coefficient as a fuzzy numbers of the form $A=\left\{\left(x_{i}, \alpha_{i}\right)\right\}_{N}$. In another word[15],

$$
\begin{gathered}
\tilde{a}, \tilde{b}, \tilde{x} \in F\left(R_{N}\right) \\
\tilde{a}=\left\{\left(a_{i}, \alpha_{i}\right)\right\}_{N}, \tilde{b}=\left\{\left(b_{i}, \alpha_{i}\right)\right\}_{N}, \tilde{x}=\left\{\left(x_{i}, \alpha_{i}\right)\right\}_{N}
\end{gathered}
$$

again using equation (7) to solve equation (6)

$$
\tilde{a} \tilde{x}+\tilde{b}=\left\{\left(a_{i} x_{i}+b_{i}, \alpha_{i}\right)\right\}_{N}
$$

Finally the fuzzy equation

$$
\tilde{a} \tilde{x}+\tilde{b}=\tilde{x}
$$

implies that $\forall \alpha_{i} \in[0,1], i=1, \ldots, N$

$$
a_{i} x_{i}+b_{i}=x_{i} \rightarrow x_{i}=\frac{b_{i}}{1-a_{i}}, a_{i} \neq 1
$$

So the solution of the fuzzy equation (6) is a fuzzy number

$$
\tilde{x}=\left\{\left(\frac{b_{i}}{1-a_{i}}, \alpha_{i}\right)\right\}_{N}
$$

Fuzzy function of crisp Variable

Two points of view can be developed depending on whether the image of $x \in X$ is a fuzzy set $\tilde{f}(x)$ on $Y$, or $x$ is mapped to $y$ through a fuzzy set of functions .

Definition 6:

A fuzzy mapping $\tilde{F}$ is a mapping from $\mathrm{X}$ to the set non empty fuzzy sets on $\mathrm{X}$, namely $\tilde{P}(x)$. In other words, to each $x \in X$, corresponds a fuzzy set $\tilde{F}(x)$ defined on $X$, whose membership function is $\mu_{\tilde{F}(x)}$ and [8]

$$
\mu_{\widetilde{\mathrm{F}}(\mathrm{x})}: \mathrm{X} \rightarrow \mathrm{I}
$$

A fuzzy set of mapping $\mathrm{F}$ can be constructed in the following way,

Define a function $\mathrm{F}: \mathrm{X} \rightarrow \widetilde{\mathrm{P}}(\mathrm{x})$ such that $\mu_{\mathrm{F}}: \mathrm{R}^{\mathrm{X}} \rightarrow \mathrm{I}$, ( where $R^{X}$ is the set of all functions $f: X \rightarrow R$ )

$$
\mu_{\mathrm{F}}(\mathrm{f})=\operatorname{Inf}\left\{\mu_{\widetilde{\mathrm{F}}(\mathrm{x})}(\mathrm{f}(\mathrm{x}) \mid \mathrm{x} \in \mathrm{X}\}\right.
$$

Definition 7: Given a fuzzy set of mappings $\mathrm{F}$ with $\mu_{\mathrm{F}}: \mathrm{R}^{\mathrm{X}} \rightarrow \mathrm{I}$, we can construct a fuzzy function $\tilde{\mathrm{F}}: \mathrm{X} \rightarrow$ $\widetilde{\mathrm{P}}(\mathrm{x})$ such that $\widetilde{\mathrm{F}}(\mathrm{x})$ is a fuzzy set, as follows[21]:

$$
\mu_{\widetilde{\mathrm{F}}(\mathrm{x})}(\mathrm{y})=\left\{\begin{array}{c}
\sup \left\{\mu_{\mathrm{F}}(\mathrm{f}) \mid \mathrm{x} \in \mathrm{f}^{-1}(\mathrm{y})\right\} \text { when } \mathrm{f}^{-1} \neq \phi \\
0, \text { when } \mathrm{f}^{-1}=\phi
\end{array}\right.
$$

Definition 8:

Given a fuzzy function set $F$ on $X$ with $\mu_{\mathrm{F}}: \mathrm{X} \rightarrow \mathrm{I}$ and $\mathrm{a}$ function $\mathrm{T}: \mathrm{X} \rightarrow \mathrm{Y}$. Then there exists a fuzzy function $\widetilde{\mathrm{T}}(\mathrm{F}): \mathrm{Y} \rightarrow \widetilde{\mathrm{P}}(\mathrm{y})$ with $\mu_{\widetilde{\mathrm{T}}(\mathrm{F})}: \mathrm{Y} \rightarrow \mathrm{I}$ such that[25]

$$
\forall y \in Y, \mu_{\tilde{T}(F)}(y)=\operatorname{Sup}\left\{\mu_{F}(x) \mid \forall x \in X, y=T(x)\right\}
$$

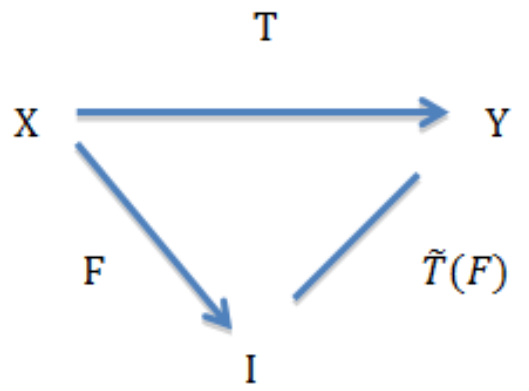

Fig. 4. fuzzy function $\widetilde{T}(F)$.

Definition 9: Given a fuzzy set of mappings $F$ with $\mu_{F}: R^{x} \rightarrow I$ and a functional $\rho: R^{x} \rightarrow R$. Then we can construct a fuzzy functional $\rho: \tilde{R}^{x} \rightarrow \tilde{R}$ such that[27]

$$
\dot{\rho}(\tilde{F})=\tilde{\rho}(F)
$$

Therefore $\forall y \in R$

$$
\mu_{\dot{\rho}(\tilde{F})}(y)=\mu_{\widetilde{\rho}(F)}(y)=\operatorname{Sup}\left\{\mu_{F}(f) \mid f \in R^{x}, y=\rho(f)\right\}
$$

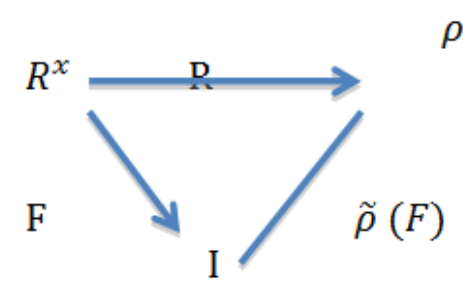

Fig. 5. fuzzy functional.

Example 1:

Let $\mathrm{G}$ be the set of all integrable functions. The integration $\int_{\mathrm{x}}: \mathrm{G} \subseteq \mathrm{R}^{\mathrm{x}} \rightarrow \mathrm{R}$, can be considered as a functional where $\int_{x} f \in R$.

Then the fuzzy integral $\int_{\mathrm{x}}: \widetilde{\mathrm{R}}^{\mathrm{x}} \rightarrow \tilde{\mathrm{p}}(\mathrm{R})$ can be defined the equation above

Given a fuzzy mapping $\tilde{\mathrm{F}}: \mathrm{X} \rightarrow \widetilde{\mathrm{P}}(\mathrm{x})$, then $\exists$ a fuzzy mapping F with $\mu_{\mathrm{F}}: \mathrm{G} \subseteq \mathrm{R}^{\mathrm{x}} \rightarrow \mathrm{I}$ such that

$$
\mu_{\int_{\mathrm{x}} \widetilde{\mathrm{F}}}(\mathrm{y})=\mu_{\int_{\mathrm{x}} \mathrm{F}}(\mathrm{y})=\operatorname{Sup}\left\{\mu_{\mathrm{F}}(\mathrm{f}) \mid \mathrm{f} \in \mathrm{R}^{\mathrm{x}}, \mathrm{y}=\int_{\mathrm{x}} \mathrm{f}\right\}
$$

Definition 10:

Let $\mathrm{T}$ be a fuzzy set such that $\mathrm{T}: \mathrm{X} \rightarrow \mathrm{R}$, then $\mathrm{T}$ will be finite if $\operatorname{supp}(\mathrm{T})=\left\{\mathrm{x}_{\mathrm{i}}\right\}$. In another word, $\mathrm{T}=\left\{\left(\mathrm{x}_{\mathrm{i}}, \alpha_{\mathrm{i}}\right)\right\}_{\mathrm{n}}$ where $\mu_{\mathrm{T}}\left(\mathrm{x}_{\mathrm{i}}\right)=\alpha_{\mathrm{i}}>0$

Definition 11: rewrite the definition 8 , if fuzzy mapping $\tilde{\mathrm{F}}: \mathrm{X} \rightarrow \widetilde{\mathrm{P}}(\mathrm{X})$ is finite, then $\widetilde{\mathrm{F}}$ can be written as

$$
\tilde{\mathrm{F}}(\mathrm{x})=\left\{\left(\mathrm{f}_{\mathrm{i}}(\mathrm{x}), \alpha_{\mathrm{i}}\right)\right\}_{\mathrm{n}}
$$

Any fuzzy set of mapping $\mathrm{F}$, constructed from $\tilde{F}$ also will be finite, and

$$
\mu_{\mathrm{F}}(\mathrm{f})=\operatorname{Inf}\left\{\mu_{\widetilde{\mathrm{F}}(\mathrm{x})}(\mathrm{f}(\mathrm{x})) \mid \mathrm{x} \in \mathrm{X}\right\}=\alpha_{\mathrm{i}} \text { if and only if } \mathrm{f}=\mathrm{f}_{\mathrm{i}}
$$

This implies that $\mathrm{F}=\left\{\left(\mathrm{f}_{\mathrm{i}}, \alpha_{\mathrm{i}}\right)\right\}_{\mathrm{n}}$ 
Now, if given a finite set of mappings $F=\left\{\left(f_{i}, \alpha_{i}\right)\right\}_{n}$, then we have

$$
\begin{gathered}
\mu_{\widetilde{\mathrm{F}}(\mathrm{x})}(\mathrm{y})=\operatorname{Sup}\left\{\mu_{\mathrm{F}}(\mathrm{f}) \mid \mathrm{y}=\mathrm{f}(\mathrm{x})\right. \\
\Rightarrow \mu_{\widetilde{\mathrm{F}}(\mathrm{x})}(\mathrm{y})=\alpha_{\mathrm{i}} \text { if and only if } \mathrm{y}=\mathrm{f}_{\mathrm{i}}(\mathrm{x}) \\
\Rightarrow \widetilde{\mathrm{F}}(\mathrm{x})=\left\{\left(\mathrm{f}_{\mathrm{i}}(\mathrm{x}), \alpha_{\mathrm{i}}\right)\right\}_{\mathrm{n}}
\end{gathered}
$$

Definition 12:

Given a finite mapping $F(x)=\left\{\left(f_{i}(x), \alpha_{i}\right)\right\}_{n}$, and a

$$
\mu_{\int_{\mathrm{x}} \widetilde{\mathrm{F}}}(\mathrm{y})=\mu_{\int_{\mathrm{x}} \mathrm{F}}(\mathrm{y})=\operatorname{Sup}\left\{\alpha_{\mathrm{i}} \mid \forall \mathrm{i}=1,2, \ldots \mathrm{n}, \mathrm{y}=\int_{\mathrm{x}} \mathrm{f}_{\mathrm{i}}\right.
$$

Definition 14: Starting from the fuzzy mapping $\widetilde{F}: \mathrm{X} \rightarrow$ $\widetilde{\mathrm{P}}(\mathrm{x})$ with $\mu_{\widetilde{\mathrm{F}}(\mathrm{x})}: \mathrm{X} \rightarrow \mathrm{I}$, for any $\alpha \in(0,1]$, we can define the $\alpha$ - cut of $\tilde{\mathrm{F}}$, denoted by $\widetilde{\mathrm{F}}_{\alpha}$ as follows $[17,24]$ :

$$
\forall \mathrm{x} \in \mathrm{X}, \widetilde{\mathrm{F}}_{\alpha}(\mathrm{x})=\left\{\mathrm{y} \mid \mu_{\widetilde{\mathrm{F}}(\mathrm{x})}(\mathrm{y}) \geq \alpha\right\}
$$

For a fuzzy set of mappings $\mathrm{F}$ with $\mu_{\mathrm{F}}: \mathrm{R}^{\mathrm{x}} \rightarrow \mathrm{I}$, the $\alpha-$ cut of $\mathrm{F}$ is the ordinary set $\mathrm{F}_{\alpha}$ and it can be constructed using (13) as

$$
\begin{array}{r}
\mathrm{F}_{\alpha}=\left\{\mathrm{f}: \mathrm{X} \rightarrow \mathrm{R} \mid \forall \mathrm{x} \in \mathrm{X}, \mathrm{f}(\mathrm{x}) \in \widetilde{\mathrm{F}}_{\alpha}(\mathrm{x})\right\} \\
\left\{\mathrm{f}: \mathrm{X} \rightarrow \mathrm{R} \mid \operatorname{Inf}_{\mathrm{x} \in \mathrm{X}} \mu_{\widetilde{\mathrm{F}}(\mathrm{x})}(\mathrm{f}(\mathrm{x}))=\mu_{\mathrm{F}}(\mathrm{f}) \geq \alpha\right\}
\end{array}
$$

Theorem 2: [19]Let A be a fuzzy set such hat $A \in$ $\widetilde{\mathrm{P}}(\mathrm{x})$, and $\mathrm{f}: \mathrm{X} \rightarrow \mathrm{Y}$ then

$$
\mathrm{f}(\mathrm{A})=\mathrm{U}_{\alpha} \alpha \mathrm{f}\left(\mathrm{A}_{\alpha}\right)
$$

Theorem 3: [11] let $\tilde{\mathrm{F}}: \mathrm{X} \rightarrow \widetilde{\mathrm{P}}(\mathrm{x})$ be a fuzzy function.Due to above theoerm we always ha

$$
\begin{aligned}
\int_{\mathrm{x}} \tilde{\mathrm{F}}=\mathrm{U}_{\alpha} \alpha\left(\int_{\mathrm{x}} \tilde{\mathrm{F}}\right)_{\alpha}=\mathrm{U}_{\alpha} \alpha\left(\int_{\mathrm{x}} \mathrm{F}_{\alpha}\right) \\
\mathrm{f}^{+}{ }_{\alpha}(\mathrm{x}) \geq \mathrm{f}^{+}{ }_{\alpha}(\mathrm{x}) \geq \mathrm{f}(\mathrm{x}) \geq \mathrm{f}^{-}{ }_{\alpha}(\mathrm{x}) \geq \mathrm{f}^{-}{ }_{\alpha}(\mathrm{x}), \forall \alpha, \alpha \text { with } \alpha \leq \alpha
\end{aligned}
$$

These functions will be called $\alpha$ - level curves of $\tilde{\mathrm{f}}$

Definition 15:

Let a fuzzy function $\tilde{\mathrm{f}}(\mathrm{x}):[\mathrm{a}, \mathrm{b}] \subseteq \mathrm{R} \rightarrow \mathrm{R}$, such that for all $\mathrm{x} \in[\mathrm{a}, \mathrm{b}], \tilde{\mathrm{f}}(\mathrm{x})$ is a fuzzy number and $\mathrm{f}^{+}{ }_{\alpha}$ and $\mathrm{f}_{\alpha}{ }^{-}$are $\alpha$ - level curves as defined in equation (20), [22,27]

The fuzzy integral of $\tilde{f}(x)$ over $[a, b]$ is then defined as the fuzzy set

$$
\tilde{\mathrm{I}}(\mathrm{a}, \mathrm{b})=\left\{\left(\mathrm{I}^{-}{ }_{\alpha}+\mathrm{I}^{+}{ }_{\alpha}, \alpha\right) \mid \alpha \in(0,1]\right\}
$$

where $\tilde{\mathrm{I}}^{-}{ }_{\alpha}=\int_{\mathrm{a}}^{\mathrm{b}} \mathrm{f}_{\alpha}{ }^{-}(\mathrm{x}) \mathrm{dx}$ and $\mathrm{I}^{+}{ }_{\alpha}=\int_{\mathrm{a}}^{\mathrm{b}} \mathrm{f}^{+}{ }_{\alpha}(\mathrm{x}) \mathrm{dx}$ and + stands for the union opertors

Remark 5:

1- A fuzzy mapping having a one curve will be called a normalized fuzzy mapping

2- A continuous fuzzy mapping is a fuzzy mapping $\tilde{\mathrm{f}}(\mathrm{x})$ such that $\mu_{\tilde{\mathrm{f}}(\mathrm{x})}(\mathrm{y})$ is continuous for all $\mathrm{x} \in \mathrm{I} \subset$ $\mathrm{R}$, and all $\mathrm{y} \in \mathrm{R}$

3- The concept of fuzzy interval is convex, normalized fuzzy set of $\mathrm{R}$ whose membership function is continuous. which is also continuous $; \mathrm{f}^{+}{ }_{\alpha}(\mathrm{x})$ and $\mathrm{f}^{-}{ }_{\alpha}(\mathrm{x})$ are defined such that

\section{8. $\alpha$ - Level Fuzzifying Function $\tilde{f}(x)$}

Consider a fuzzy function, which shall be integrated over the crisp interval. The fuzzy function $\tilde{\mathrm{f}}(\mathrm{x})$ is supposed to be fuzzy number; we shall further assume that $\alpha$ - level curves[3,8,17]:

$$
\mu_{\tilde{\mathrm{f}}(\mathrm{x})}=\alpha, \forall \alpha \in[0,1]
$$

have exactly two continuous solutions:

$$
\mathrm{y}=\mathrm{f}^{+}{ }_{\alpha}(\mathrm{x}) \text { and } \mathrm{y}=\mathrm{f}^{-}{ }_{\alpha}(\mathrm{x}), \text { for all } \alpha \neq 1
$$

and only one solution:

$$
y=f(x) \text { for } \alpha=1
$$

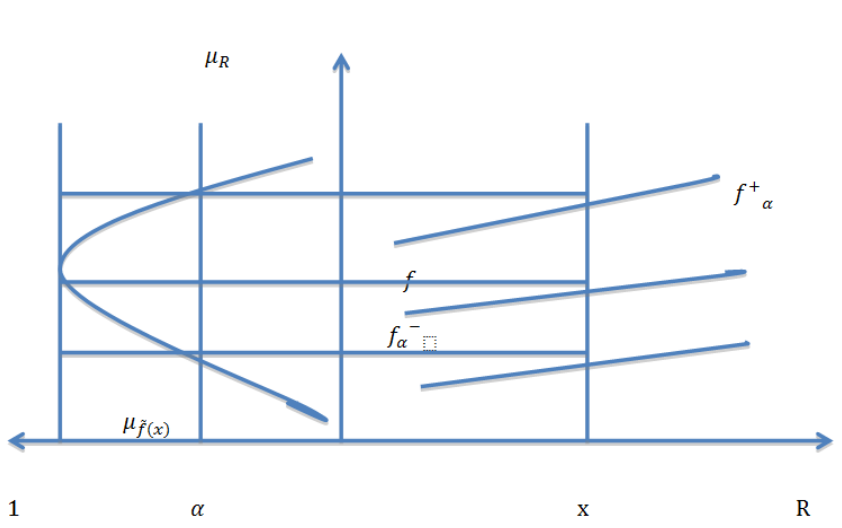

Fig. 6. $\alpha$-level fuzzifying function.

Definition 16:.A fuzzy mapping $\tilde{\mathrm{F}}$ such that $\tilde{\mathrm{F}}: \mathrm{X} \rightarrow \tilde{\mathrm{p}}(\mathrm{X})$, in other words, to each

$$
\mathrm{x} \in \mathrm{X} \text {, corresponds a fuzzy } \tilde{\mathrm{F}}(\mathrm{x}) \text { defined on } \mathrm{X} \text {, }
$$
whose membership function is $\mu_{\widetilde{F}}: X \rightarrow I$.

A fuzzy set of mapping $F$ can be constructed in the following way, Define a function $F: X \rightarrow \tilde{p}(X)$ such that 
$\mu_{\mathrm{F}}: \mathrm{R}^{\mathrm{x}} \rightarrow \mathrm{I},\left(\right.$ where $\mathrm{R}^{\mathrm{x}}$ is the set of all functions $\left.\mathrm{f}: \mathrm{X} \rightarrow \mathrm{R}\right)$.

$$
\mu_{\mathrm{F}}(f)=\inf \left\{\mu_{\tilde{F}(x)}(f(x)) \mid x \in X\right\}
$$

\section{Fuzzy Operator}

In the $\mathrm{Eq}(21)$. we consider a fuzzy mapping $\tilde{F}$ such that $\tilde{F}: X \rightarrow \tilde{p}(X)$ with $\mu_{F}: X \rightarrow I$. The functional of $\rho$ over $\mathrm{X}$ was defined as a fuzzy set $\rho^{*}(\tilde{F})$.

In this part, we shall deal with the operator of fuzzy function $\mathrm{F}$, which will denoted $\mathcal{J}^{*}(\tilde{F})[5,13,26]$

In this part, we shall deal with the operator of fuzzy function $\mathrm{F}$, which will denoted $\mathcal{J}^{*}(\tilde{F})[5,13,26]$

Definition $17:$ Given a fuzzy function $\tilde{F}: X \rightarrow \tilde{P}(X)$ with $\mu_{\tilde{F}}: X \rightarrow I$ and an operator

$\mathcal{J}: R^{x} \rightarrow R^{x}$. Then we can construct a fuzzy operator $\mathcal{J}^{*}: \tilde{R}^{x} \rightarrow \tilde{R}^{x}$ such that

$$
\mathcal{J}^{*}(\tilde{F})=\overline{\tilde{\mathcal{J}}(F)}
$$

Therefore $, \forall y \in R, \forall x \in X$

$$
\mu_{\mathcal{J}^{*}(\widetilde{F})(x)}(y)=\mu_{\overline{\tilde{\jmath}(F)(x)}}(y)=\operatorname{Sup}\left\{\mu_{\tilde{\tilde{J}}(F)}(g) \mid \forall g \in R^{x}, y=\right.
$$

$$
=\operatorname{Sup}\left\{\sup \mu_{\mathrm{F}}(\mathrm{f}) \mid \forall \mathrm{f}, \mathrm{g} \in \mathrm{R}^{\mathrm{x}}, \mathrm{y}=\mathcal{J}(\mathrm{f})\right\} \mathrm{y}=\mathrm{g}(\mathrm{x})
$$

When $\mathcal{J}$ is non=-to-one operator then equation (21) will be

$$
\mu_{\mathcal{J}^{*}(\widetilde{\mathrm{F}})(\mathrm{x})}(\mathrm{y})=\operatorname{Sup}\left\{\mu_{\mathrm{F}}(\mathrm{f}) \mid \forall \mathrm{f} \in \mathrm{R}^{\mathrm{x}}, \mathrm{y}=\mathcal{J}(\mathrm{f})(\mathrm{x})\right\}
$$

Lemma1:

Let $\mathrm{F}$ be a fuzzy mapping $\mu_{\mathrm{F}}: \mathrm{X} \rightarrow \mathrm{I}$, Let $\mathrm{T}$ and $\mathrm{H}$ be two operator such that $\mathrm{T}: \mathrm{X} \rightarrow \mathrm{Y}, \mathrm{H}: \mathrm{Y} \rightarrow \mathrm{Z}$, and $\mathrm{H}$ is one-to-one then we have

$$
\widetilde{\mathrm{H}} \widetilde{\mathrm{T}}(\mathrm{F})=\overline{\mathrm{HT}}(\mathrm{F})
$$

proof:

\section{$\forall \in \mathrm{Z}$}

$$
\begin{aligned}
& \mu_{\tilde{\mathrm{H}} \widetilde{\mathrm{T}}}(\mathrm{z})=\operatorname{Sup}_{2}\left\{\mu_{\widetilde{\mathrm{T}}}(\mathrm{y}) \mid \forall \mathrm{y} \in \mathrm{Y}, \mathrm{z} \in \mathrm{H}(\mathrm{y})\right. \\
& =\operatorname{Sup}\left\{\sup \left\{\mu_{\mathrm{F}}(\mathrm{x}) \mid \forall \mathrm{x} \in \mathrm{X}, \mathrm{y}=\mathrm{T}(\mathrm{x}), \forall \mathrm{z}=\mathrm{H}(\mathrm{y})\right\}\right\}
\end{aligned}
$$

Since $\mathrm{H}$ is one -to-one, then

$$
\begin{gathered}
\mu_{\widetilde{\mathrm{H}} \widetilde{\mathrm{T}}}(\mathrm{z})=\operatorname{Sup}\left\{\mu_{\mathrm{F}}(\mathrm{x}) \mid \forall \mathrm{x} \in \mathrm{X}, \mathrm{z}=\mathrm{H}(\mathrm{T}(\mathrm{x}))=(\mathrm{HT})(\mathrm{x})\right\} \\
=\mu_{\overline{\mathrm{HT}}}(\mathrm{z})
\end{gathered}
$$

Theorem 4: [8]

Let $\tilde{\mathrm{F}}$ be a fuzzy mapping $\mu_{\widetilde{\mathrm{F}}}: \mathrm{X} \rightarrow \mathrm{I}$, and I, $\mathcal{J}$ be two operators $I, \mathcal{J}: R^{x} \rightarrow R^{x}$ where $\mathcal{J}$ is one-to-one. Then there exist a fuzzy operators $I^{*}, \mathcal{J}^{*}: \widetilde{\mathrm{R}}^{\mathrm{x}} \rightarrow \widetilde{\mathrm{R}}^{\mathrm{x}}$ such that

$$
\mathcal{J}^{*} \mathrm{I}^{*}(\widetilde{\mathrm{F}})=(\mathrm{I} \mathcal{J})^{*}(\widetilde{\mathrm{F}})
$$

Proof:

$$
\mathcal{J}^{*} \mathrm{I}^{*}(\tilde{\mathrm{F}})=\mathcal{J}^{*}\left(\tilde{\mathrm{I}}(\mathrm{F})=\overline{\tilde{\mathcal{J}}(\tilde{\mathrm{I}}(\mathrm{F}))}=(\mathrm{I} \mathcal{J})^{*}(\tilde{\mathrm{F}})\right.
$$

By Lemma, we have

$$
\begin{gathered}
\tilde{\mathcal{J}} \tilde{\mathrm{I}}(\mathrm{F})=\overline{\mathcal{J}}(\mathrm{F}) \\
\mathcal{J}^{*} \mathrm{I}^{*}(\tilde{\mathrm{F}})=\overline{\tilde{\mathcal{J}} \tilde{\mathrm{I}}(\mathrm{F})}=\overline{\overline{\mathcal{J}} \mathrm{I}(\mathrm{F})}=(\mathrm{I} \mathcal{J})^{*}(\tilde{\mathrm{F}})
\end{gathered}
$$

Definition 18. Given a finite fuzzy set of mappings $=\left\{\left(\mathrm{f}_{\mathrm{i}}, \alpha_{\mathrm{i}}\right)\right\}_{\mathrm{n}}$, and an operator

$\mathcal{J}: \mathrm{R}^{\mathrm{x}} \rightarrow \mathrm{R}^{\mathrm{x}}$. The fuzzy operator $\mathcal{J}^{*}: \widetilde{\mathrm{R}}^{\mathrm{x}} \rightarrow \widetilde{\mathrm{R}}^{\mathrm{x}}$ of $\mathrm{F}$ can be defined by

$$
\forall \mathrm{y} \in \mathrm{R}^{\mathrm{x}}
$$

$$
\mu_{\mathcal{J}^{*}(\widetilde{\mathrm{F}})}(\mathrm{y})=\mu_{\overline{\tilde{\jmath}}(\mathrm{F})}(\mathrm{y})=\operatorname{Sup}\left\{\alpha_{\mathrm{i}} \mid \text { for all } \mathrm{i}=1, \ldots, \mathrm{n} \mathrm{y}=\mathcal{J}\left(\mathrm{f}_{\mathrm{i}}\right)\right\}
$$

If $\mathcal{J}$ is a one-to-one equation (90) will be

$$
\begin{gathered}
\mu_{\mathcal{J}^{*}(\widetilde{\mathrm{F}})}(\mathrm{y})=\mu_{\tilde{\mathfrak{J}}(\mathrm{F})}(\mathrm{y})=\alpha_{\mathrm{i}} \text { if and only if } \mathrm{y}=\mathcal{J}\left(\mathrm{f}_{\mathrm{i}}\right) \\
\Rightarrow \mathcal{J}^{*}(\widetilde{\mathrm{F}})=\mathcal{J}^{*}\left\{\left(\mathrm{f}_{\mathrm{i}}, \alpha_{\mathrm{i}}\right)\right\}_{\mathrm{n}}=\left\{\left(\mathcal{J}\left(\mathrm{f}_{\mathrm{i}}\right), \alpha_{\mathrm{i}}\right)\right\}_{\mathrm{n}}
\end{gathered}
$$

Remarks 6:[25]

Given a fuzzy mapping $\widetilde{F}$ and $\widetilde{G}$. Then we have

$$
\text { i- } \quad(\widetilde{F}+\widetilde{G})(x)=\widetilde{F}(x)+\widetilde{G}(x)
$$

ii- $\quad(\widetilde{\mathrm{F}} \cdot \widetilde{\mathrm{G}})(\mathrm{x})=\tilde{\mathrm{F}}(\mathrm{x}) \cdot \widetilde{\mathrm{G}}(\mathrm{x})$

iii- $(\mathrm{c} \tilde{\mathrm{F}})(\mathrm{x})=\mathrm{c} \tilde{\mathrm{F}}(\mathrm{x})$

Theorem 5: let $\tilde{F}$ and $\widetilde{G}$ be real fuzzy mapping from $X$ to the set $\widetilde{P}(\mathrm{x})$ such that

$$
\widetilde{\mathrm{F}}=\left\{\left(\mathrm{f}_{\mathrm{i}}, \alpha_{\mathrm{i}}\right)\right\}_{\mathrm{n}}, \widetilde{\mathrm{G}}=\left\{\left(\mathrm{g}_{\mathrm{i}}, \beta_{\mathrm{i}}\right)\right\}_{\mathrm{n}} . \text { Then }
$$

i- $\mathcal{J}^{*}(\widetilde{\mathrm{F}}+\widetilde{\mathrm{G}})=\mathcal{J}^{*}(\widetilde{\mathrm{F}})+\mathcal{J}^{*}(\widetilde{\mathrm{G}})$

ii- $\mathcal{J}^{*}\left(\int_{0}^{\mathrm{x}} \widetilde{\mathrm{F}}(\mathrm{x}-\mathrm{t}) \widetilde{\mathrm{G}}(\mathrm{t}) \mathrm{dt}\right)=\mathcal{J}^{*}(\widetilde{\mathrm{F}})(\mathrm{s}) \cdot \mathcal{J}^{*}(\widetilde{\mathrm{G}})(\mathrm{s})$

Proof :

(i)

$$
(\widetilde{\mathrm{F}}+\widetilde{\mathrm{G}})(\mathrm{x})=\widetilde{\mathrm{F}}(\mathrm{x})+\widetilde{\mathrm{G}}(\mathrm{x})=\left\{\left(\mathrm{f}_{\mathrm{i}}+\mathrm{g}_{\mathrm{i}}\right), \gamma_{\mathrm{ij}}\right\}
$$

Where $\gamma_{\mathrm{ij}}=\operatorname{Max}_{\mathrm{i}, \mathrm{j}}\left\{\operatorname{Min}\left(\alpha_{\mathrm{i}}, \beta_{\mathrm{j}}\right)\right\}$

(ii)

$$
\begin{gathered}
\mathcal{J}^{*}\left(\int_{0}^{\mathrm{x}} \tilde{\mathrm{F}}(\mathrm{x}-\mathrm{t}) \widetilde{\mathrm{G}}(\mathrm{t}) \mathrm{dt}\right)=\mathcal{J}^{*}\left(\int_{0}^{\mathrm{x}}\left(\left\{\mathrm{f}_{\mathrm{i}}(\mathrm{x}-\mathrm{t}), \alpha_{\mathrm{i}}\right\} \cdot\left\{\mathrm{g}_{\mathrm{i}}(\mathrm{x}), \beta_{\mathrm{j}}\right\}\right) \mathrm{dt}\right. \\
=\mathcal{J}^{*} \int_{0}^{\mathrm{x}}\left\{\mathrm{f}_{\mathrm{i}}(\mathrm{x}-\mathrm{t}) \cdot \mathrm{g}_{\mathrm{j}}(\mathrm{x}), \gamma_{\mathrm{ij}}\right\} \mathrm{dt} \\
\left.\left\{\mathcal{J} \int_{0}^{\mathrm{x}} \mathrm{f}_{\mathrm{i}}(\mathrm{x}-\mathrm{t}) \cdot \mathrm{g}_{\mathrm{j}}(\mathrm{t})\right) \mathrm{dt}, \gamma_{\mathrm{ij}}\right\}
\end{gathered}
$$




$$
\begin{aligned}
= & \left\{\mathcal{J}\left(\mathrm{f}_{\mathrm{i}}(\mathrm{x}) \cdot \mathcal{J}\left(\mathrm{g}_{\mathrm{j}}(\mathrm{t})\right), \gamma_{\mathrm{ij}}\right\}\right. \\
= & \left\{\mathcal{J}\left(\mathrm{f}_{\mathrm{i}}\right)(\mathrm{s}), \alpha_{\mathrm{i}}\right\} \cdot\left\{\mathcal{J}\left(\mathrm{g}_{\mathrm{j}}(\mathrm{s}), \beta_{\mathrm{j}}\right\}\right. \\
= & \mathcal{J}^{*}(\widetilde{\mathrm{F}})(\mathrm{s}) \cdot \mathcal{J}^{*}(\widetilde{\mathrm{G}})(\mathrm{s})
\end{aligned}
$$

Definition 19:

Let $R$ be the set of real number and $\widetilde{P}(R)$ all fuzzy subsets defined on R. G.Zang defined the fuzzy number ã $\in F(R)$ as follows :

$\tilde{\mathrm{a}}$ is normal, that is there exists $\mathrm{x} \in \mathrm{R}$ such that $\mu_{\tilde{\mathrm{a}}}(\mathrm{x})=1$

Foe every $\alpha \in(0,1], \mathrm{a}_{\alpha}=\left\{\mathrm{x}: \mu_{\tilde{\mathrm{a}}}(\mathrm{x}) \geq \alpha\right\}$ is closed

1- $\tilde{\mathrm{c}}=\tilde{\mathrm{a}}+\tilde{\mathrm{bifc}}^{-}{ }_{\alpha}=\mathrm{a}^{-}{ }_{\alpha}+\mathrm{b}^{-}{ }_{\alpha}$ and $\mathrm{c}^{+}{ }_{\alpha}=\mathrm{a}^{+}{ }_{\alpha}+\mathrm{b}^{+}{ }_{\alpha}$, forevery $\alpha \in[0,1]$

2- $\tilde{\mathrm{c}}=\tilde{\mathrm{a}}-\tilde{\mathrm{bifc}}{ }^{-}{ }_{\alpha}=\mathrm{a}^{-}{ }_{\alpha}-\mathrm{b}^{+}{ }_{\alpha}$ and $\mathrm{c}^{+}{ }_{\alpha}=\mathrm{a}^{+}{ }_{\alpha}-\mathrm{b}^{-}{ }_{\alpha}$, forevery $\alpha \in[0,1]$

3- $\tilde{\mathrm{c}}=\tilde{\mathrm{a}} \cdot \tilde{\mathrm{b} i f c^{-}}{ }_{\alpha}=\operatorname{Min}\left[\mathrm{a}^{-} \cdot \mathrm{b}^{-}{ }_{\alpha}, \mathrm{a}^{-}{ }_{\alpha} \cdot \mathrm{b}^{+}{ }_{\alpha}, \mathrm{a}^{+}{ }_{\alpha}, \mathrm{b}^{-}{ }_{\alpha}, \mathrm{a}^{+}{ }_{\alpha} \cdot \mathrm{b}^{+}{ }_{\alpha}\right]$

$\mathrm{c}^{+}{ }_{\alpha}=\mathrm{Mxa}\left[\mathrm{a}^{-} \cdot \mathrm{b}^{-}{ }_{\alpha}, \mathrm{a}^{-}{ }_{\alpha} \cdot \mathrm{b}^{+}{ }_{\alpha}, \mathrm{a}^{+}{ }_{\alpha}, \mathrm{b}^{-}{ }_{\alpha}, \mathrm{a}^{+}{ }_{\alpha} \cdot \mathrm{b}^{+}{ }_{\alpha}\right]$, forevery $\alpha \in(0,1]$

4- $\widetilde{\mathrm{c}}=\tilde{\mathrm{a}} / \tilde{\mathrm{b}}$ if c ${ }^{-}{ }_{\alpha}=\operatorname{Min}\left[\mathrm{a}^{-}{ }_{\alpha} / \mathrm{b}^{-}{ }_{\alpha}, \mathrm{a}^{-}{ }_{\alpha} / \mathrm{b}^{+}{ }_{\alpha}, \mathrm{a}^{+}{ }_{\alpha} / \mathrm{b}^{-}{ }_{\alpha}, \mathrm{a}^{+}{ }_{\alpha} / \mathrm{b}^{+}{ }_{\alpha}\right], \mathrm{c}^{+}{ }_{\alpha}=\operatorname{Mxa}\left[\mathrm{a}^{-}{ }_{\alpha} / \mathrm{b}^{-}{ }_{\alpha}, \mathrm{a}^{-}{ }_{\alpha} / \mathrm{b}^{+}{ }_{\alpha}, \mathrm{a}^{+}{ }_{\alpha} / \mathrm{b}^{-}{ }_{\alpha}, \mathrm{a}^{+}{ }_{\alpha} /\right.$

$\mathrm{b}^{+}{ }_{\alpha}$ ], forevery $\alpha \in(0,1]$, excludinghecase $\mathrm{b}^{-}{ }_{\alpha}=0$ or $\mathrm{b}^{+}{ }_{\alpha}=0$

5- forevery $\mathrm{k} \in \mathrm{R}$ andã $\in \mathrm{F}(\mathrm{R}), \mathrm{ka}=\mathrm{U}_{\alpha \in[0,1]} \alpha\left[\mathrm{ka}^{-}{ }_{\alpha}, \mathrm{ka}^{+}{ }_{\alpha}\right]$ if $\mathrm{k} \geq 0$

$=\mathrm{U}_{\alpha \in[0,1]} \alpha\left[\mathrm{ka}^{+}{ }_{\alpha}, \mathrm{ka}^{-}{ }_{\alpha}\right]$ if $\mathrm{k}<0$

6- $\tilde{\mathrm{a}} \leq \tilde{\mathrm{b}}$ if $\mathrm{a}^{-}{ }_{\alpha} \leq \mathrm{b}^{-}{ }_{\alpha}$ and $\mathrm{a}^{+}{ }_{\alpha} \leq \mathrm{b}^{+}{ }_{\alpha}$ forevery $\alpha \in(0,1]$

7- $\tilde{\mathrm{a}} \leq \tilde{\mathrm{b}}$ ifa ${ }^{-}{ }_{\alpha} \leq \mathrm{b}^{-}{ }_{\alpha}$ and there exists $\alpha \in(0,1]$ such that $\mathrm{a}^{-}{ }_{\alpha}<\mathrm{b}^{-}{ }_{\alpha}$ or $\mathrm{a}^{+}{ }_{\alpha}<\mathrm{b}^{+}{ }_{\alpha}$

$8-\mathrm{a}^{+}{ }_{\alpha}=\mathrm{b}^{+}{ }_{\alpha}$ ifã $\leq \tilde{\mathrm{b}}$ and $\tilde{\mathrm{b}} \leq \tilde{\mathrm{a}}$ forevery $\alpha \in(0,1]$

Definition 21: Let $\tilde{A} \subset F(R)$

1- If there exists $\widetilde{M} \in F(R)$ such that $\tilde{a} \leq \widetilde{M}$ for every $\widetilde{a} \in \widetilde{A}$, then $\widetilde{A}$ is said to have an upper bound $\widetilde{\mathrm{M}}$.

2- If there exists $\widetilde{\mathrm{m}} \in \mathrm{F}(\mathrm{R})$ such that $\widetilde{\mathrm{m}} \leq \tilde{\mathrm{a}}$ for every $\tilde{a} \in \widetilde{A}$, then $\widetilde{A}$ is said to have an lower bound $\widetilde{m}$.

3- $\widetilde{A}$ is said to be bounded if $\widetilde{A}$ has both upper and lower bounds.

A sequence $\left\{\tilde{a}_{n}\right\} \subset F(R)$ is said to be bounded if the set $\left\{\widetilde{\mathrm{a}}_{\mathrm{n}} \mid \mathrm{n} \in \mathrm{N}\right\}$ is bounded

Definition 22: Let $(X, d)$ be a metric space, and let $H(x)$ be the set of all non-empty compact subset of $X$. The distance between $A$ and $B$, for each $A, B \in H(x)$ is defined by the Hausdorff metric [18,27]

$$
\widetilde{D}(\widetilde{A}, \widetilde{B})=\operatorname{Sup}_{0 \leq \alpha \leq 1} D\left(A_{\alpha}, B_{\alpha}\right)=\operatorname{Sup}_{0 \leq \alpha \leq 1}\left\{\operatorname{Max}\left\{\operatorname{Sup}_{a \in A_{\alpha}} \operatorname{Inf}_{b \in B_{\alpha}} d(a, b), \operatorname{Sup}_{b \in B_{\alpha}} \operatorname{Inf}_{a \in A_{\alpha}} d(a, b)\right\}\right\}
$$

where $\mathrm{D}$ is the Haousdorff metric defined in $\mathrm{H}(\mathrm{x})$

Theorem 7: $(H(F(x), \widetilde{D})$ is a metric space, if $(X, d)$ is a metric space

Theorem 8: $(\mathrm{H}(\mathrm{F}(\mathrm{x}), \widetilde{\mathrm{D}})$ is complete metric space ,if $(\mathrm{X}, \mathrm{d})$ is a complete metric space.

Now, when $X=R$ and $d(u, v)=|u-v|$ for all $u, v \in R$,

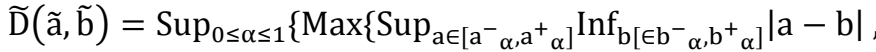

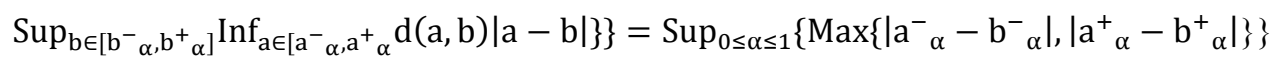

Theorem 5.(F(R), $\widetilde{D})$ is a metric space

Theorem 6. If $\tilde{a}, \tilde{b}, \tilde{c} \in F(R)$ then $\widetilde{D}(\tilde{a}+\widetilde{c}, \tilde{b}+\widetilde{c})=\widetilde{D}(\tilde{a}, \tilde{b})$

Proof:

$$
\widetilde{\mathrm{D}}(\tilde{\mathrm{a}}+\tilde{\mathrm{c}}, \tilde{\mathrm{b}}+\tilde{\mathrm{c}})=\operatorname{Sup}_{\alpha \in(0,1]}\left(\mathrm{D}(\tilde{\mathrm{a}}+\tilde{\mathrm{c}})_{\alpha},(\tilde{\mathrm{b}}+\tilde{\mathrm{c}})_{\alpha}\right)=\operatorname{Sup}_{\alpha \in(0,1]}\left(\mathrm{D}\left[\mathrm{a}^{-}{ }_{\alpha}+\mathrm{c}^{-}{ }_{\alpha}, \mathrm{a}^{+}{ }_{\alpha}+\mathrm{c}^{+}{ }_{\alpha}\right)_{\alpha},\left[\mathrm{b}^{-}{ }_{\alpha}+\mathrm{c}^{-}{ }_{\alpha}, \mathrm{b}^{+}{ }_{\alpha}+\mathrm{c}^{+}{ }_{\alpha}\right)_{\alpha}\right)=
$$
$\operatorname{Sup}_{\alpha \in(0,1]} \operatorname{Max}\left\{\left|\left(\mathrm{a}^{-}{ }_{\alpha}+\mathrm{c}^{-}{ }_{\alpha}\right)-\left(\mathrm{b}^{-}{ }_{\alpha}+\mathrm{c}^{-}{ }_{\alpha}\right)\right|,\left|\left(\mathrm{a}^{+}{ }_{\alpha}+\mathrm{c}^{+}{ }_{\alpha}\right)-\left(\mathrm{b}^{+}{ }_{\alpha}+\mathrm{c}^{+}{ }_{\alpha}\right)\right|\right\}=\operatorname{Sup}_{\alpha \in(0,1]} \operatorname{Max}\left\{\left|\mathrm{a}^{-}{ }_{\alpha}-\mathrm{b}^{-}{ }_{\alpha}\right|,\left|\mathrm{a}^{+}{ }_{\alpha}-\mathrm{b}^{+}{ }_{\alpha}\right|\right\}=$ $\widetilde{\mathrm{D}}(\tilde{\mathrm{a}}, \tilde{\mathrm{b}})$ 
definition 25. Let $\left\{\tilde{a}_{n}\right\} \subset F(R), \tilde{a} \in F(R)$. Then the sequence $\left\{\tilde{a}_{\mathrm{n}}\right\}$ is said to converge to $\tilde{\mathrm{a}}$ in fuzzy distance $\widetilde{\mathrm{D}}$, denoted by

$$
\lim _{n \rightarrow \infty} \tilde{a}_{n}=\tilde{a}
$$

if for any given $\varepsilon>0$ there exists an integer $\mathrm{N}>$ 0 such that $\widetilde{\mathrm{D}}\left(\widetilde{\mathrm{a}}_{\mathrm{n}}, \widetilde{\mathrm{a}}\right)<\varepsilon$ for $\mathrm{n} \geq \mathrm{N}$. A sequence $\left\{\tilde{a}_{n}\right\}$ in $F(R)$ is said to be a Cauchy sequence if for every $\varepsilon>0$, there exists an integer $N>0$ such that

$$
\widetilde{\mathrm{D}}\left(\widetilde{\mathrm{a}}_{\mathrm{n}}, \widetilde{\mathrm{a}}_{\mathrm{m}}\right)<\varepsilon
$$

For $\mathrm{n}, \mathrm{m}>N$. A fuzzy metric space $(\mathrm{F}(\mathrm{R}), \mathrm{D})$ is called the complete metric space if every Cauchy sequence in $F(R)$ is converges .

Theorem 7. The sequence $\left\{\tilde{a}_{n}\right\}$ in $F(R)$ is converge in the metric $\widetilde{D}$ if and only if $\left\{\widetilde{a}_{n}\right\}$ is a Cauchy sequence .

Theorem 8. (F(R), $\widetilde{D})$ is a complete metric space

Definition 26: A fuzzy mapping $\tilde{F}: X \rightarrow F(R)$ is called levelwise continuous at $t_{0} \in X$ if the mapping $\widetilde{F}_{\alpha}$ is continuous at $t=t_{0}$ with respect to the Hausdorff metric Don $\mathrm{F}(\mathrm{R})$ for all $\alpha \in(0,1]$. As a special case whenX $=[\mathrm{a}, \mathrm{b}] \subseteq \mathrm{R}$, this definition can be generalized to $[a, b] \times[a, b]$ as follows:

Definition 27: A fuzzy mapping $\tilde{\mathrm{f}} \mathrm{X} \times \mathrm{X} \rightarrow \mathrm{F}(\mathrm{R})$ is called levelwise continuous at point $\left(\mathrm{x}_{0}, \mathrm{t}_{0}\right) \in \mathrm{X} \times \mathrm{X}$ provided, for any fixed $\alpha \in[0,1]$ and arbitrary $\varepsilon>0$ there exists $\delta(\varepsilon, \alpha)>$ 0 such that

$$
\mathrm{D}\left(|\tilde{\mathrm{f}}(\mathrm{x}, \mathrm{t})|_{\alpha},\left|\tilde{\mathrm{f}}\left(\mathrm{x}_{0}, \mathrm{t}_{0}\right)\right|_{\alpha}\right)<\varepsilon
$$

whenever

$$
\left|\mathrm{t}-\mathrm{t}_{0}\right|<\delta,\left|\mathrm{x}-\mathrm{x}_{0}\right|<\delta
$$

for all $\mathrm{x}, \mathrm{t} \in \mathrm{X}$

Definition 28:

Let

$\tilde{F}: X \rightarrow F(R)$, the integral of $\tilde{F}$ over $X=$

$[\mathrm{a}, \mathrm{b}]$ denoted by $\int_{\mathrm{x}} \tilde{\mathrm{F}}(\mathrm{t}) \mathrm{dt}$ is defined levelwise by the equation

$$
\begin{gathered}
{\left[\int_{\mathrm{X}} \tilde{\mathrm{F}}(\mathrm{t}) \mathrm{dt}\right]_{\alpha}=\int_{\mathrm{x}} \tilde{\mathrm{F}}_{\alpha}(\mathrm{t}) \mathrm{dt} \text { for all } 0<\alpha \leq 1} \\
{\left[\int_{\mathrm{X}} \tilde{\mathrm{F}}^{-}{ }_{\alpha}(\mathrm{t}) \mathrm{dt}, \int_{\mathrm{x}} \tilde{\mathrm{F}}^{+}{ }_{\alpha}(\mathrm{t}) \mathrm{dt}\right]}
\end{gathered}
$$

Theorem 9. If $\tilde{\mathrm{F}}: \mathrm{X} \rightarrow \mathrm{F}(\mathrm{R})$ levelwise continuous and $\operatorname{Supp}(\tilde{\mathrm{F}})$ is bounded, then $\mathrm{F}$ is integrable

Proof: Directly from definition (27)

Theorem 10.Let $F, G: X \rightarrow F(R)$ be integrable and $\in R$. Then

$$
\begin{aligned}
& 1-\int_{x}\left(F(t)+G(t) d t=\int_{x} F(t) d t+\int_{x} G(t) d t\right. \\
& 2-\int_{x} \lambda F(t) d t=\lambda \int_{x} F(t) d t
\end{aligned}
$$

Theorem 10:

(Existence and uniqueness For a Solution Of fuzzy nonlinear integral Equation )
Assume the following conditions are satisfied $1-\mathrm{f}:[\mathrm{a}, \mathrm{b}] \rightarrow \mathrm{E}^{\mathrm{n}}$ is countinuous and bounded $2-\mathrm{K}: \Delta \rightarrow \mathrm{E}^{\mathrm{n}}$ is a continuous function

$3-$ if $\mathrm{u}, \mathrm{v}:[\mathrm{a}, \mathrm{b}]$

$\rightarrow \mathrm{E}^{\mathrm{n}}$ are contious, then the lipschitz condition

$$
\mathrm{D}(\mathrm{K}(\mathrm{x}, \mathrm{t}, \mathrm{u}(\mathrm{t})), \mathrm{K}(\mathrm{x}, \mathrm{t}, \mathrm{v}(\mathrm{t}))) \leq \mathrm{LD}(\mathrm{u}(\mathrm{x}), \mathrm{v}(\mathrm{x}))
$$

is satisfied, with $0<L<\frac{1}{\mathrm{~b}-\mathrm{a}}$.

where $\Delta=\{(\mathrm{x}, \mathrm{t}, \mathrm{u}, \mathrm{v}) \mid \mathrm{a} \leq \mathrm{x}, \mathrm{t} \leq \mathrm{b},-\infty \leq \mathrm{v} \leq \infty,-\infty \leq \mathrm{u} \leq$ v\}.

\section{Solution of Fuzzy Nonlinear Integral Equations}

Our treatment of fuzzy nonlinear volterra ntegral equation centerel mainly on illustrations of the known methods of finding exact, or numerical solution. In this paper we present new techniques for solving fuzzy nonlinear volterra integral equations by using Honotopy analysis method .

\subsection{Homotopy Analysis Method}

Consider

$$
N[u]=u(x)-f(x)-\int_{a}^{x} k(x, t) u(t) d t
$$

Where $N$ is an operator $f(x)$ is known function and $\mathrm{x}$ is independent variable.

Let $u_{0}(x)$ denoted an initial guess of the exact solution $u(x), h \neq 0$ an auxiliary parameter, $H(x) \neq 0$ an auxiliary function, and $L$ auxiliary linear operator, with the property $L[r(x)]=0$ when $r(x)=0$. Then using $q \in[0,1]$ as an embedding parameter, we construct such a homotopy.

$$
\begin{array}{r}
(1-q) L\left[\phi(x, q)-u_{0}(x)\right]-q h H(x) N[\phi(x, q)]= \\
\widehat{H}\left[\phi(x, q) ; u_{0}(x), H(x) h, q\right]
\end{array}
$$

It should be emphasized that we have great freedom to choose the initial guess $u_{0}(x)$ the auxiliary linear operator $L$, the non-zero auxiliary parameter $h$, and the auxiliary function $H(x)$.

Enforcing the homotopy (25) to zero, i.e

$$
\widehat{H}\left[\phi(x, q) ; u_{0}(x), H(x) h, q\right]=0
$$

we have the so - called zero- order deformation equation

$$
(1-q) L\left[\phi(x, q)-u_{0}(x)\right]=q h H(x) N[\phi(x, q)]
$$

When $q=0$, the zero-order deformation equation (26) becomes

$$
\phi(x ; 0)=u_{0}(x)
$$

and when $q=1$ since $h \neq 0$ and $H(x) \neq 0$, the zero-order deformation equation (26) is equivalent to

$$
\emptyset(x, 1)=u_{1}(x)
$$


Thus according to (27) and (28), as the embedding parameter $q$ increases from 0 to $1, \phi(x, q)$ varies continuously. From the initial $u_{0}(x)$ the exact solution $(x)$. Such a kind of continuous variation is called deformation in homotopy .

By Taylor's theorem $\emptyset(x, q)$ can be expanded in power series of $q$ as follows

$$
\emptyset(x, q)=u_{0}(x)+\sum_{m=1}^{\infty} u_{m}(x) q^{m}
$$

Where

$$
u_{m}(x)=\left.\frac{1}{m !} \frac{\partial^{m} \phi(x, q)}{\partial q^{m}}\right|_{q=0}
$$

If the initial guess $u_{0}(x)$, the auxiliary linear parameter $L$, the non zero auxiliary parameter $\mathrm{h}$, and the auxiliary function $H(x)$ are property chosen so that the power series (29) of $\phi(x, q)$ converges at $q=1$, we have under these assumptions the solution series .

$$
\begin{array}{r}
u(x)=\phi(x, 1)=u_{0}(x)+\sum_{m=1}^{\infty} u_{m}(x) q^{m} \\
u_{m}(x)=\chi_{m} u_{m-1}(x)+h\left[u_{m-1}(x)-f(x)\right. \\
-\int_{a}^{x} k(x, t) u_{m-1}(t) d t \\
\chi_{m}=\left\{\begin{array}{l}
0 \text { if } m \leq 1 \\
1 \text { if } m>1
\end{array}\right.
\end{array}
$$

Finaly we get

$$
\begin{gathered}
u_{0}(x)=\phi(x, 0) \\
u_{1}(x)=-h f(x) \\
u_{m}(x)=(1+h) u_{m-1}(x)-h\left[\int_{a}^{x} k(x, t) u_{m-1}(t) d t\right]
\end{gathered}
$$

Where

$$
m \geq 2
$$

Hence, the solution of equation (24)

$$
u(x)=\lim _{p \rightarrow 1} u(x, p)=\sum_{m=1}^{\infty} u_{m}(x)
$$

we denoted the nth- order approximation to solve $u_{m}(x)=$ $\sum_{m=1}^{n} u_{m}(x)$

\subsection{Solve Fuzzy HAM}

Consider the fuzzy nonlinear integral equation with fuzzy difference kernel

$$
\tilde{u}(x)=\tilde{f}(x)+\int_{a}^{x} \tilde{k}(x-t) \tilde{u}(t) d t
$$

Where

$\tilde{u}(x)=\left\{\left(u_{i}(x), \alpha_{i}\right)\right\}_{n}, \tilde{f}(x)=\left\{\left(f_{i}(x), \alpha_{i}\right)\right\}_{n}$ and $\tilde{k}(x-$ $t)=\left\{\left(k_{i}(x-t), \alpha_{i}\right)\right\}_{n}$

Then

$$
\begin{aligned}
\left\{\left(u_{i}(x), \alpha_{i}\right)\right\}_{n}=\{ & \left.\left(f_{i}(x), \alpha_{i}\right)\right\}_{n} \\
& +\int_{a}^{x}\left\{\left(k_{i}(x-t), \alpha_{i}\right)\right\}_{n}\left\{\left(u_{i}(t), \alpha_{i}\right)\right\}_{n} d t
\end{aligned}
$$

Now, make use equation (7), we get

$$
\begin{aligned}
\left\{\left(u_{i}(x), \alpha_{i}\right)\right\}_{n}= & \left\{\left(f_{i}(x), \alpha_{i}\right)\right\}_{n}+\left\{\left(\int_{a}^{x} k_{i}(x\right.\right. \\
& \left.\left.-t) u_{i}(t) d t, \alpha_{i}\right)\right\}_{n}
\end{aligned}
$$

and by equation (8)

$$
\left\{\left(u_{i}(x), \alpha_{i}\right)\right\}_{n}=\left\{\left(f_{i}(x)+\int_{a}^{x} k_{i}(x-t) u_{i}(t) d t, \alpha_{i}\right)\right\}_{n}
$$

which implies that for each $\forall \alpha_{i} \in[0,1]$

$$
u_{i}(x)=f_{i}(x)+\int_{a}^{x} k_{i}(x, t) u_{i}(t) d t \forall i=1,2, \ldots \ldots, n
$$

Now, we can apply the HAM to equation (32), we get

$$
N[u]=u_{i}(x)-f_{i}(x)-\int_{a}^{x} k_{i}(x, t) u_{i}(t) d t
$$

Let $q \in[0,1]$

$$
\begin{gathered}
(1-q) L\left[\phi_{i}(x, q)-u_{i 0}(x)\right]-q h H(x) N\left[\phi_{i}(x, q)\right] \\
=\widehat{H}\left[\phi_{i}(x, q) ; u_{i 0}(x), H(x) h, q\right] \\
\widehat{H}\left[\phi_{i}(x, q) ; u_{i 0}(x), H(x) h, q\right]=0 \\
(1-q) L\left[\phi_{i}(x, q)-u_{i 0}(x)\right]=q h H(x) N\left[\phi_{i}(x, q)\right]
\end{gathered}
$$

When $\mathrm{q}=0$

$$
\phi_{i}(x ; 0)=u_{i 0}(x)
$$

when $\mathrm{q}=1$

$$
\begin{gathered}
\emptyset_{i}(x, 1)=u_{i 1}(x) \\
\emptyset_{i}(x, q)=u_{i 0}(x)+\sum_{m=1}^{\infty} u_{i m}(x) q^{m}
\end{gathered}
$$

Where

$$
\begin{gathered}
u_{i m}(x)=\left.\frac{1}{m i !} \frac{\partial^{i m} \phi_{i}(x, q)}{\partial q^{i m}}\right|_{q=0} \\
u_{i}(x)=\phi_{i}(x, 1)=u_{i 0}(x)+\sum_{m=1}^{\infty} u_{i m}(x) q^{i m} \\
u_{i m}(x)=\chi_{m} u_{i m-1}(x)+h\left[u_{i m-1}(x)-f_{i}(x)\right. \\
-\int_{a}^{x} k_{i}(x, t) u_{i m-1}(t) d t \\
\chi_{m}=\left\{\begin{array}{l}
0 \text { if } m \leq 1 \\
1 \text { if } m>1
\end{array}\right.
\end{gathered}
$$


Finally we get

$$
\begin{gathered}
u_{i 0}(x)=\phi_{i}(x, 0) \\
u_{i 1}(x)=-h f_{i}(x) \\
u_{i m}(x)=(1+h) u_{i m-1}(x)-h\left[\int_{a}^{x} k_{i}(x, t) u_{i m-1}(t) d t\right]
\end{gathered}
$$

Where

\section{$m \geq 2$}

$$
u_{i}(x)=\lim _{p \rightarrow 1} u_{i}(x, p)=\sum_{m=1}^{\infty} u_{i m}(x)
$$

we denoted the nth- order approximation to solve $u_{i m}(x)=$ $\sum_{m=1}^{n} u_{i m}(x), \forall i=1,2 \ldots ., n$

Example 1

Consider the fuzzy nonlinear integral equation

$$
\begin{gathered}
\tilde{u}(x)=\tilde{f}(x)+\int_{a}^{x} \tilde{k}(x, t) \tilde{u}^{2}(t) d t \\
\tilde{f}(x)=\left\{\left(f_{1}, 0.4\right),\left(f_{2}, 1\right)\right\} \\
f_{1}(x)=\ln (\mathrm{x}+1)+2 \ln 2(1-\mathrm{x} \ln 2+\mathrm{x})-2 \mathrm{x}-\frac{5}{4}, f_{2}(x)=\sin (\pi \mathrm{x}) \\
\tilde{k}_{1}(x, t) \tilde{u}^{2}{ }_{1}(t)=(x-t) u_{1}{ }^{2}(t), \tilde{k}_{2}(x, t) \tilde{u}_{2}^{3}(t) \\
=\frac{1}{5} \cos (\pi \mathrm{x}) \sin (\pi \mathrm{t}) u^{3}{ }_{2}(t)
\end{gathered}
$$

with the exact solution to equation is $u_{1}(x)=\ln (x+1)$, and

$$
u_{2}(x)=\sin (\pi x)+\frac{20-\sqrt{391}}{3} \cos (\pi x)
$$

by using equation (9), and (10)

Where

$$
\begin{gathered}
\tilde{u}(x)=\left\{\left(u_{i}(x), \alpha_{i}\right)\right\}_{n}, \tilde{f}(x)=\left\{\left(f_{i}(x), \alpha_{i}\right)\right\}_{n} \text { and } \tilde{k}(x-t) \\
=\left\{\left(k_{i}(x-t), \alpha_{i}\right)\right\}_{n}
\end{gathered}
$$

Then

$$
\begin{aligned}
\left\{\left(u_{i}(x), \alpha_{i}\right)\right\}_{n}=\left\{\left(f_{i}(x), \alpha_{i}\right)\right\}_{n} \\
\\
+\int_{a}^{x}\left\{\left(k_{i}(x-t), \alpha_{i}\right)\right\}_{n}\left\{\left(u_{i}(t), \alpha_{i}\right)\right\}_{n} d t
\end{aligned}
$$

Now , make use equation (7), we get

$$
\begin{aligned}
\left\{\left(u_{i}(x), \alpha_{i}\right)\right\}_{n}= & \left\{\left(f_{i}(x), \alpha_{i}\right)\right\}_{n}+\left\{\left(\int_{a}^{x} k_{i}(x\right.\right. \\
& \left.\left.-t) u_{i}(t) d t, \alpha_{i}\right)\right\}_{n}
\end{aligned}
$$

and by equation (8)

$$
\left\{\left(u_{i}(x), \alpha_{i}\right)\right\}_{n}=\left\{\left(f_{i}(x)+\int_{a}^{x} k_{i}(x-t) u_{i}(t) d t, \alpha_{i}\right)\right\}_{n}
$$

which implies that for each $\forall \alpha_{i} \in[0,1]$

$$
\begin{aligned}
u_{1}(x)=\ln (\mathrm{x}+1) & +2 \ln 2(1-\mathrm{x} \ln 2+\mathrm{x})-2 \mathrm{x}-\frac{5}{4} \\
+ & \int_{a}^{x}(x-t) u_{1}{ }^{2}(t) d t
\end{aligned}
$$

by using HAM method to solve this formula, we get

$$
u_{10}(x)=0
$$

$$
\begin{gathered}
u_{11}(x)=-h\left(\ln (\mathrm{x}+1)+2 \ln 2(1-\mathrm{x} \ln 2+\mathrm{x})-2 \mathrm{x}-\frac{5}{4}\right. \\
u_{12}(x)=(1+h) u_{11}(x)-\int_{a}^{x}(x-t) u_{11}^{2}(t) d t \\
u_{1 m}(x)=(1+h) u_{1 m-1}(x)-\int_{a}^{x}(x-t) u_{1 m-1}^{2}(t) d t
\end{gathered}
$$

Table 1. shows numerical result calculated according the exact solution and Homotopy analysis method for $u_{1 m}$, where $h=0.5$.

\begin{tabular}{llll}
\hline $\mathbf{x}_{\mathbf{i}}$ & $\begin{array}{l}\text { Exact } \mathbf{u}_{\mathbf{1}}(\mathbf{x})=\ln (\mathbf{x}+ \\
\mathbf{1})\end{array}$ & $\mathbf{H A M} \mathbf{u}_{\mathbf{1} \mathbf{m}}(\mathbf{x})$ & Exact-HAM \\
\hline 0 & $(0,0.4)$ & $(0.00000026768,0.4)$ & $\begin{array}{l}2.56186267595 \mathrm{E}- \\
8\end{array}$ \\
& & & $2.53309949127 \mathrm{E}-$ \\
0.1 & $(0.095310179804,0.4)$ & $(0.95310206285,0.4)$ & 8 \\
& & & $2.19432191028 \mathrm{E}-$ \\
0.2 & $(0.182321556793,0.4)$ & $(0.182321579887,0.4)$ & 8 \\
& & & $1.45529119865 \mathrm{E}-$ \\
0.3 & $(0.262364264467,0.4)$ & $(0.262364280170,0.4)$ & 8 \\
& & & $1.06476171213 \mathrm{E}-$ \\
0.4 & $(0.336472236621,0.4)$ & $(0.336472248418,0.4)$ & 8 \\
0.5 & $(0.405465108108,0.4)$ & $(0.405465120209,0.4)$ & $1.84023705163 \mathrm{E}-$ \\
& & & 8 \\
0.6 & $(0.470003629245,0.4)$ & $(0.470003629794,0.4)$ & $6.84976264597 \mathrm{E}-$ \\
& & & 9 \\
0.7 & $(0.530628251062,0.4)$ & $(0.587786677053,0.4)$ & $\begin{array}{l}6.0872384910 \mathrm{E}- \\
10\end{array}$ \\
0.8 & $(0.587786664902,0.4)$ & $(0.587786677053,0.4)$ & $3.5510718809 \mathrm{E}-9$ \\
0.9 & $(0.641853886172,0.4)$ & $(0.641853890141,0.4)$ & $2.8196508461 \mathrm{E}-9$ \\
1 & $(0.693147180559,0.4)$ & $(0.693147181293,0.4)$ & $4.163761557 \mathrm{E}-10$ \\
\hline
\end{tabular}

Table 1 solution to the example 1

$$
u_{2}(x)=\sin (\pi \mathrm{x})+\int_{a}^{x} \frac{1}{5} \cos (\pi \mathrm{x}) \sin (\pi \mathrm{t}) u_{2}^{3}(t) d t
$$

at $\alpha=1$

by using the equation (9) and (10), we get

$$
\begin{gathered}
u_{20}(x)=0 \\
u_{21}(x)=-h(\sin (\pi \mathrm{x})) \\
u_{22}(x)=(1+h) u_{21}(x)-\int_{a}^{x} \frac{1}{5} \cos (\pi \mathrm{x}) \sin (\pi \mathrm{t}) u_{21}{ }^{3}(t) d t \\
u_{2 m}(x)=(1+h) u_{2 m-1}(x) \\
-\int_{a}^{x} \frac{1}{5} \cos (\pi \mathrm{x}) \sin (\pi \mathrm{t}) u_{2 m-1}{ }^{3}(t) d t
\end{gathered}
$$


Table 2. shows numerical result calculated according the exact solution and Homotopy analysis method for $u_{2 m}$, where $h=0.5$.

\begin{tabular}{|c|c|c|c|}
\hline$x_{i}$ & $\begin{array}{l}\text { Exact } u_{2}(x)= \\
\sin (\pi x)+ \\
\frac{20-\sqrt{391}}{3} \cos (\pi x) .\end{array}$ & HАM $u_{2 m}(x)$ & Exact-HАМ \\
\hline 0 & $(0.0754266889,1)$ & $(0.0754266889,1)$ & $\begin{array}{l}5.53723733531 \mathrm{E}- \\
15\end{array}$ \\
\hline 0.1 & $(0.3807520383,1)$ & $(0.3807520383,1)$ & $\begin{array}{l}5.21804821573 \mathrm{E}- \\
15\end{array}$ \\
\hline 0.2 & $(0.6488067254,1)$ & $(0.6488067254,1)$ & $4.55191440096-15$ \\
\hline 0.3 & $(0.8533516897,1)$ & $(0.8533516897,1)$ & $3.21964677141-15$ \\
\hline 0.4 & $(0.9743646449,1)$ & $(0.9743646449,1)$ & $1.77635683940-15$ \\
\hline 0.5 & $(1.0000000000,1)$ & $(1.0000000000,1)$ & 0 \\
\hline 0.6 & $(0.9277483875,1)$ & $(0.9277483875,1)$ & $\begin{array}{l}1.77635683940 \mathrm{E}- \\
15\end{array}$ \\
\hline 0.7 & $(0.7646822990,1)$ & $(0.7646822990,1)$ & $\begin{array}{l}3.21964677141 \mathrm{E}- \\
15\end{array}$ \\
\hline 0.8 & $(0.5267637791,1)$ & $(0.5267637791,1)$ & $\begin{array}{l}4.55191440096 \mathrm{E}- \\
15\end{array}$ \\
\hline 0.9 & $(0.2372819503,1)$ & $(0.2372819503,1)$ & $\begin{array}{l}0.52735593669 \mathrm{E}- \\
15\end{array}$ \\
\hline 1 & $(-0.0754266889,1)$ & $(-0.0754266889,1)$ & $\begin{array}{l}0.55372373353 \mathrm{E}- \\
15\end{array}$ \\
\hline
\end{tabular}

Table 2 solution to the example 1

\section{Conclusion}

The proposed method is a powerful procedure for solving fuzzy nonlinear integral equations. The examples analyzed illustrate the ability and reliability of the method presented in this paper and reveals that this one is very simple and effective. The obtained solutions, in comparison with exact solutions admit a remarkable accuracy. Results indicate that the convergence rate is very fast, and lower approximations can achieve high accuracy.

\section{References}

[1] C. T. H. Baker, A perspective on the numerical treatment of volterra equations, Journal of Computational and Applied Mathematics, 125 (2000), 217-249.

[2] N.Boldik, M. Inc, Modified decomposition method for nonlinear Volterra-Fredholm integral equations, Chaos, Solution and Fractals 33 (2007) 308- 313. http://dr.doi.org/10.1016/j.chaos.2005.12.058

[3] M. I. Berenguer, D. Gamez, A. I. Garralda-Guillem, M. Ruiz Galan and M. C. Serrano Perez, Biorthogonal systems for solving volterra integral equation systems of the second kind, Journal of Computational and Applied Mathematics, 235 (2011), 1875-1883.

[4] A. M. Bica, Error estimation in the approximation of the solution of nonlinear fuzzy fredholmintegral equations, Information Sciences, 178 (2008), 1279-1292.

[5] A. H. Borzabadi and O. S. Fard, A numerical scheme for a class of nonlinear fredholmintegral equations of the second kind, Journal of Computational and Applied Mathematics, 232 (2009), 449-454.

[6] S. S. L. Chang and L. Zadeh, On fuzzy mapping and control, IEEE Trans. System Man Cybernet, 2 (1972), 30-34.
[7] Y. Chen and T. Tang, Spectral methods for weakly singular volterra integral equations with smooth solutions, Journal of Computational and Applied Mathematics, 233 (2009), 938950 .

[8] D. Dubois and H. Prade, Operations on fuzzy numbers, International Journal of Systems Science, 9 (1978), 613-626.

[9] D. Dubois and H. Prade, Towards fuzzy differential calculus, Fuzzy Sets and Systems, 8(1982), 1-7.

[10] A. Kaufmann and M. M. Gupta, Introduction fuzzy arithmetic, Van Nostrand Reinhold, NewYork, 1985.

[11] J. P. Kauthen, Continuous time collocation method for volterra-fredholm integral equations, Numerical Math., 56 (1989), 409-424.

[12] P. Linz, Analytical and numerical methods for volterra equations, SIAM, Philadelphia, PA,1985.

[13] O. Solaymani Fard and M. Sanchooli, Two successive schemes for numerical solution of linearfuzzy fredholm integral equations of the second kind, Australian Journal of Basic Applied Sciences, 4 (2010), 817-825.

[14] L. A. Zadeh, The concept of a linguistic variable and its application to approximate reasoning, Information Sciences, 8 (1975), 199-249.

[15] S. Abbasbandy, E. Babolian and M. Alavi, Numerical method for solving linear fredholm fuzzy integral equations of the second kind, Chaos Solitons \& Fractals, 31 (2007), 138-146.

[16] E. Babolian, H. S. Goghary and S. Abbasbandy, Numerical solution of linear fredholm fuzzy integral equations of the second kind by Adomian method, Applied Mathematics and Com-putation, 161 (2005), 733-744.

[17] Alabdullatif, M., Abdusalam, H. A. and Fahmy, E. S., Adomain decomposition method for nonlinear reaction diffusion system of Lotka- Volterra type, International Mathematical Forum, 2, No. 2 (2007), pp. 87-96.

[18] WazWaz, A.-M., The modified decomposition method for analytic treatment of nonlinearintegral equations and system of non-linear integral equations, International Journal of Computer Mathematics, Vol. 82, No. 9(2005), pp. 1107-1115.

[19] R. Goetschel and W. Vaxman, Elementary fuzzy calculus, Fuzzy Sets and Systems, 18 (1986), 31-43.

[20] T. Allahviranloo and M. Otadi, Gaussian quadratures for approximate of fuzzy multipleintegrals, Applied Mathematics and Computation, 172 (2006), 175-187.

[21] Kaleva, O.: A note on fuzzy differential equations, Nonlinear Analysis 64, 895-900 (2006).

[22] O. Kaleva, Fuzzy differential equations, Fuzzy Sets and Systems, 24 (1987), 301-317.

[23] M. Ma, M. Friedman and A. Kandel, A new fuzzy arithmetic, Fuzzy Sets and Systems, 108 (1999), 83-90

[24] G. J. Klir, U. S. Clair and B. Yuan, Fuzzy set theory: foundations and applications, Prentice-Hall, 1997.

[25] W. Congxin and M. Ming, On embedding problem of fuzzy number spaces, Part 1, Fuzzy Setsand Systems, 44 (1991), 3338. 
[26] M. L. Puri and D. Ralescu, Fuzzy random variables, Journal of Mathematical Analysis and Applications, 114 (1986), 409-422.

[27] Eman A.hussain, Existence and uniqueness of the solution of nonlinear integral equation, Department of mathematics /college of science, university of Al-mustansiriyah Iraq/ Baghdad ,vol.26(2)2013. 